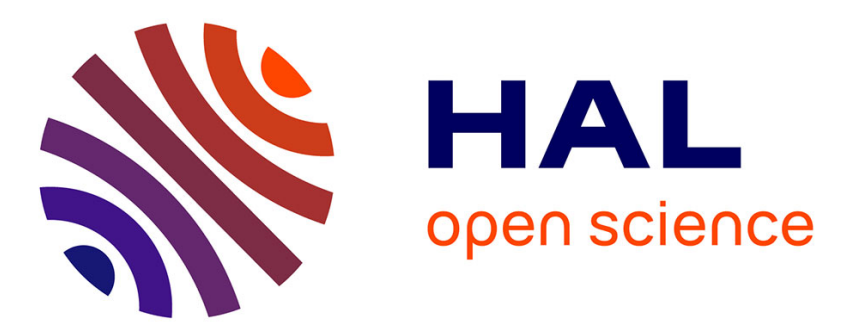

\title{
Quiet Time Ionopheric Irregularities Over the African Equatorial Ionization Anomaly Region
}

Paul O Amaechi, Elijah O Oyeyemi, Andrew O Akala, Elijah O Falayi, Mohammed Kaab, Zouhair Benkhaldoun, Christine Amory-Mazaudier

\section{To cite this version:}

Paul O Amaechi, Elijah O Oyeyemi, Andrew O Akala, Elijah O Falayi, Mohammed Kaab, et al.. Quiet Time Ionopheric Irregularities Over the African Equatorial Ionization Anomaly Region. Radio Science, 2020, 55 (8), pp.e2020RS007077. 10.1029/2020RS007077 . hal-02925992

\section{HAL Id: hal-02925992 https://hal.science/hal-02925992}

Submitted on 31 Aug 2020

HAL is a multi-disciplinary open access archive for the deposit and dissemination of scientific research documents, whether they are published or not. The documents may come from teaching and research institutions in France or abroad, or from public or private research centers.
L'archive ouverte pluridisciplinaire HAL, est destinée au dépôt et à la diffusion de documents scientifiques de niveau recherche, publiés ou non, émanant des établissements d'enseignement et de recherche français ou étrangers, des laboratoires publics ou privés. 


\title{
Quiet time ionopheric irregularities over the African Equatorial Ionization Anomaly
}

(EIA) region

Paul O. Amaechi ${ }^{1}$, Elijah O. Oyeyemi ${ }^{2}$, Andrew O. Akala ${ }^{2,3,4}$, Elijah O. Falayi ${ }^{5}$, Mohammed $\mathrm{Kaab}^{6}$, Zouhair Benkhaldoun ${ }^{6}$, Christine-Amory Mazaudier ${ }^{7,8}$

${ }^{1}$ Department of Physical Sciences, Chrisland University, Abeokuta, Nigeria ${ }^{2}$ Department of Physics, University of Lagos, Yaba, Lagos, Nigeria

${ }^{3}$ Distance Learning Institute, University of Lagos, Akoka, Yaba, Lagos, Nigeria ${ }^{4}$ Maritime Institute, University of Lagos, Akoka, Yaba, Lagos, Nigeria

${ }^{5}$ Department of Physics, Tai Solarin University of Education, Ijebu-Ode, Nigeria ${ }^{6}$ Oukaimeden Observatory, LPHEA, FSSM, Cadi Ayyad University, Marrakech, Morrocco

${ }^{7}$ Sorbonne Universités, LPP, Polytechnique, Paris, France

${ }^{8}$ T/ICT4D, ICTP, Trieste, Italy

Key points:

Correspondance: Paul Amaechi (paoloobiaks@yahoo.fr)

- Influence of the anomaly strength and differential extent of the crests on irregularities over Africa.

- Asymmetry of irregularities over the crests of the African EIA in both hemispheres.

- Similarity in irregularities behavior over the northern crest and trough, and postmidnight occurrence in summer.

\begin{abstract}
This paper investigated variations of quiet time ionospheric irregularities over the African Equatorial Ionization Anomaly using the rate of change of TEC index (ROTI). Irregularities were quantified in terms of percentage occurrence and examined along with parameter of the Anomaly mainly its strength and asymmetry of the crests as well as equatorial electric field (EEF) derived from the real time equatorial electric field model and meridional wind obtained from the horizontal wind model. Irregularities occurred from 19:30 - 03:00 LT with a time difference of 1 hour between both crests. The highest occurrences were registered in April: $91.67 \%, 75.00 \%$ and $96.43 \%$ for the northern crest, trough and southern crest, respectively. Seasonally, stronger anomaly (>20 TECU) in addition to the highest EEF value in the dusk- sector corresponded with the equinoctial higher occurrence rate in both hemispheres while stronger meridional wind and farthest crests location accounted for the least occurrence in winter. The summer occurrence rate was favored by reduced meridional wind, smaller crests location and late time of prereversal enhancement at the magnetic equator. There was a significant asymmetry in irregularities over the crests in both hemispheres with stronger and greater occurrence rate over the southern crest. Also, irregularities strength and occurrence rate was similar over the northern crest and trough in summer. In addition, to dusk-sector activity, irregularities occurred during postmidnight in summer. Simultaneous variations of irregularities over the crests and trough also highlighted the contribution of non equatorial processes to their formation at the crests.
\end{abstract}

This article has been accepted for publication and undergone full peer review but has not been through the copyediting, typesetting, pagination and proofreading process which may lead to differences between this version and the Version of Record. Please cite this article as doi: 10.1029/2020RS007077 
Key words: Ionospheric irregularities, Equatorial Electric Field, Equatorial Ionization Anomaly, postmidnight irregularities.

\section{Introduction}

The Equatorial Ionization Anomaly (EIA) is a major feature of the low latitude ionosphere marked by a minimum in ionization over the magnetic equator and two regions of enhanced plasma on both sides at about \pm 20 degree (Namba \& Maeda, 1939; Appleton, 1946). It owes its existence to some complex interaction between electric field and the horizontal geomagnetic field, under the influence of gravity and pressure gradients (Kelley, 1989). The vertical ExB drift velocity whose proxy is the equatorial electrojet (EEJ) is a key mechanism driving the fountain effect thus, the development of the EIA. The EIA profile and by extension, the asymmetry in magnitude and position of the crests with respect to the magnetic equator $(\operatorname{dip}=0)$ is in turn modulated by the pattern of meridional wind blowing from one hemisphere to another (Paul \& DasGupta, 2010; Khadka et al., 2018).

During post sunset, the prereversal enhancement (PRE) in eastward electric field resulting from the dynamo action of the F-region (Farley et al., 1986; Heelis, 2004) comes into the picture. The enhanced electric field further moves ionization upward resulting in a downward movement of plasma for the rest of the night (Eccles et al., 2015). The consequent plasma redistribution is associated with a range of turbulence and instability that eventually give rise to ionospheric irregularities (Haerendel, 1973; Ossakow, 1981). The interest in the EIA thus, resides in the fact that it has direct bearing on the operational capability of Global Navigation Satellite System (GNSS) applications whose signals are liable to suffer from additional errors linked with the higher total electron content (TEC) values, large scale TEC gradients (Wanninger, 1993) and enhanced scintillations due to protuberant ionospheric irregularities (Basu et al., 1996) especially, over the crests region.

It is generally accepted that the Rayleigh-Taylor (R-T) Instability is the mechanism responsible for the formation of ionospheric irregularities (Ossakow, 1981; Zalesak et al., 1982). The equatorial plasma bubbles (EPBs) irregularities so generated at/or in the vicinity of the magnetic equator in the bottom-side post sunset F2 layer ascend, eventually extending poleward along the geomagnetic flux tube up to the crests of the EIA in both hemispheres (Kelley \& McClure, 1981; Cervera \& Thomas, 2006). The diurnal, seasonal, latitudinal and longitudinal behavior of irregularities as well as their dependence on solar and magnetic activity has been investigated (Basu et al., 1978; Aarons et al., 1980; 1997; Aarons, 1993; Huang et al., 2002). As such, it is known that the seasonal and longitudinal behavior of irregularities is influenced by transequatorial neutral wind (Maruyama \& Matuura, 1984) as well as the geographic alignment between the solar terminator and the local magnetic meridian (Tsunoda, 1985). However, the day-to-day variability still remains a subject of considerable attention because of the transient and unpredicted nature of solar and magnetospheric phenomena (geomagnetic storms) as well as disturbances propagating from the lower atmosphere which are known to affect irregularities behaviour in a rather unpredicted manner (Abdu, 2012; Yizengaw \& Groves, 2018). 
Of all longitudinal sectors under the EIA region, Africa offers the best opportunity for ionospheric irregularities research because of its vast landmass and uniqueness of processes as revealed by satellite observations (Huang et al., 2001; Burke et al., 2004; Hei et al., 2005). However, most of these features are yet to be confirmed using ground based data despite the fact that statistical differences are known to exist between satellite and ground based observations (Makela et al., 2004). To this effect, the existing network of ground based instruments in Africa has offer an unprecedented opportunity to study ionospheric processes on a continuous basis over a region which hitherto is characterized by few studies. Existing literature so far has thus, revealed features of irregularities in African such as their time of occurrence (1900 - 0400 LT) and seasonal variability with two equinoctial peaks (Ackah et al., 2011; Oladipo \& Schüler, 2013; D'ujanga \& Taabu, 2014) and some occurrences during June solstice (Akala et al., 2014) as well as the existence of longitudinal differences between Middle and East Africa (Chu et al., 2015) and western and eastern sectors (Paznukhov et al., 2012; Mungufeni et al., 2016). Other characteristics such as the equinoctial asymmetry (Seba \& Gogie, 2015; Mungufeni et al., 2016) and solar activity and geomagnetic storm variations of irregularities (Ngwira et al., 2013; Akala et al., 2016; Habarulema et al., 2017; Amaechi et al., 2018a,b) have also been reported.

Most of these works however, focused on the southern part of the geomagnetic equator which is tilted slightly northward with respect to the geographic equator over Africa. As such, simultaneous studies of quiet time irregularities over trough and crests of the EIA in both hemispheres are lacking in Africa. In addition, the contribution of the EIA to irregularities variation over this continent still requires investigation. This work thus, examined the variabilty of quiet time irregularities over the trough and crests of the African EIA during year 2013. Emphasis is placed on the (i) contribution of the EIA to irregularities variations, (ii) equinoctial asymmetry in both hemispheres (iii) origin of irregularities at the crests and

(iv) their occurrence in the post sunset and postmidnight periods.

\section{Data and method of analysis}

Primary parameters used in this study include GNSS observables and magnetometer measurements for the year 2013. This year falls within the maximum phase of solar cycle 24 with highest solar flux of $148.78 \mathrm{sfu}$. It was chosen based on simultaneous availability of sufficient data over all stations. GNSS data were obtained from the University NAVSTAR Consortium (UNAVCO) website htpp://www.unavco.org/data/ data.html. These were used to compute TEC, reconstruct the EIA and monitor ionospheric irreguarities. The magnetometer data for the Adigrat, ETHI $\left(14.3^{\circ} \mathrm{N}, 39.5^{\circ} \mathrm{E}, 6.01^{\circ} \mathrm{dip}\right)$ and Addis Ababa, AAE $\left(9.0^{\circ} \mathrm{N}\right.$, $38.8^{\circ} \mathrm{E}, 0.16^{\circ} \mathrm{dip}$ ) stations were provided by the African Meridian B-Field Education and Research (AMBER) and International Real-time Magnetic Observatory Network (INTERMAGNET), respectively. These were employed to compute the horizontal component of the earth's magnetic field $(\mathrm{H})$ and $\Delta \mathrm{H}$, a proxy for the EEJ current. The computation process involved estimating daily baseline values and hourly departure of $\mathrm{H}$ as well as correction for non cyclic variations. Further details about the processing of $\mathrm{H}$ can be found in Vestine (1947) and Rabiu et al. (2007). $\Delta H$ was estimated as the difference between the $\mathrm{H}$ measured at the two stations (i.e. $\Delta H=H_{A A E}-H_{E T H I}$ ) [Anderson et al., 2004; 
Yizengaw et al., 2014]. The geographic location of the GNSS and magnetometers stations are shown in Figure 1 while their coordinates are given in Table 1.

GNSS data were subjected to quality check using the Translating Editing and Quality Checking (TEQC) software (Estey \& Meertens, 1999). Vertical TEC (VTEC) was thereafter, processed following the method described in Seemala and Delay (2010). This involved computing slant TEC (STEC) by leveling carrier phase with the pseudorange measurements (Hansen et al., 2000), detecting and correcting cycle slips (Blewitt, 1990) and calibrating STEC using differential satellite biases published by the University of Bern and receiver bias estimated by minimizing the variability of TEC between 02:00 and 06:00 LT (Valladares et al., 2009). STEC was then converted to VTEC using a mapping function with height assumed at $350 \mathrm{~km}$ (Mannucci et al., 1993). Multipath was minimized using an elevation cut-off mask of $40^{\circ}$. Such elevation also ensured that errors related to ionospheric pierce point (IPP) and ionospheric gradient which are characteristics of the low latitude ionosphere (Rama Rao et al., 2006) were taken care of.

The EIA profile was recontructed in the post sunset from 19:00 - 22:00 LT using VTEC values within $20.81-46.40^{\circ} \mathrm{E}$ longitude at ionospheric pierce point (IPP) for individual pseudorange random noise (PRN), binned within 15 minute x 1 degree (time/latitude). EIA parameters such as the latitudinal extent of the crests with respect to the trough (L) and the strenght of the anomaly ( $\triangle \mathrm{TEC}$ ) were computed in both hemispheres. $\mathrm{L}$ is defined as the latitudinal difference between the position of the crest and trough whereas $\triangle \mathrm{TEC}$ is defined as the TEC difference between the peak and trough of the EIA (Yizengaw et al., 2009) on both sides of the magnetic equator. In addition, the differential extent which is the difference between the northern and southern extent of the crest (Paul \& Dasgupta, 2010) was estimated. These parameters were examined in line with variations of ionospheric irregularities monitored using the rate of change of TEC index (ROTI) in the post sunset period.

The suitability of ROTI in characterizing known features of equatorial spread F (ESF) has been demonstrated over time (Wanniger, 1993; Pi et al., 1997; Mendillo et al., 2000; Oladipo et al., 2014; Yizengaw and Groves, 2018). ROTI was computed as the standard deviation of the rate of change index (ROT) in the unit of TECU/min for each pair of satellite and receiver every 5 minutes interval after Pi et al. (1997) (i.e. ROTI $=\sqrt{\left.\left\langle\mathrm{ROT}^{2}\right\rangle-<R O T\right\rangle^{2}}$ ). All ROTI values were average for a particular epoch (5 minutes). The extent of occurrence was estimated in terms of percentage irregularities occurrences as given in equation 1, within 18:00 - 06:00 LT time window while an irregularities event was defined as an event during which ROTI exceeded 0.5 TECU/ min for 1 hour (Otsuka et al., 2006).

$$
\text { Percentage occurrence }=\frac{N_{\text {irreg }}}{N_{\text {all }}} \times 100
$$

where $N_{\text {irreg }}$ is the number of days with irregularities and $N_{\text {all }}$ is the number of days in a month for which data are available.

Secondary parameter such as the planetary $\mathrm{K}$ - index (Kp) was employed to select quiet days (Table 2). Kp was obtained from the International Service of Geomagnetic Indices (ISGI) 
website, isgi.unistra.fr. A day was deemed quiet if its Kp was lesser or equal to 3 (Fejer et al., 2008). In addition, the Real time model of Ionospheric Electric Fields (http://geomag.org/models/PPEFM/RealtimeEF.html) was used to predict quiet time equatorial ionospheric eastward electric field (EEF) along mean longitude $35^{\circ}$. This model uses solar wind data from the Advanced Composition Explorer (ACE) satellite to predict EEF for all longitudes. To examine the relation between $\triangle \mathrm{H}$ and EEF, the Pearson correlation coefficient (r) was estimated between both variables from 08:00 - 18:00 LT during quiet period. Based on this relation, EEF was utilized to gain insight into changes in electric field and the consequent effect on irregularities occurrence in the post sunset period.

Finally, the updated Horizontal Wind Model (HWM14) [Drob et al., 2015] was employed to study the dynamics of meridional wind over 5 stations along mean longitude $37^{\circ} \mathrm{E}$ : one located at the magnetic equator, two close to the crests and the other two away from the crests in both hemispheres. Recently, the capability of this model in predicting thermospheric wind over Africa has been demonstrated (Kaab et al., 2017; Seba et al., 2018). However, results presented in Chartier et al. (2015) showed that setting the altitude of the maximum volume emission rate at $250 \mathrm{~km}$ can lead to errors in modeling. Recent simulations of this height at the Oukaimeden observatory in Morocco during year 2015 indeed showed that this altitude varies on a daily and seasonal basis (Kaab et al., 2017). In a bid to account for this height variation we estimated the airglow-weighted HWM meridional winds $(\hat{u})$ between $200 \mathrm{~km}$ and $300 \mathrm{~km}$ using equation 2 .

$$
\hat{u}=\frac{\sum u_{z} a_{z}}{a_{z}}
$$

where $u_{z}$ are the meridional winds from HWM at altitude $\mathrm{z}$ and $a_{z}$ is the calculated redline volume emission rate at altitude $\mathrm{z}$ (Link \& Cogger, 1988).

For the seasonal distribution, we took the average values of the months of November, December, January, February and those of May, June, July, August to represent winter and summer, respectively. It is important to recall that winter/summer in the northern hemisphere correspond to summer/winter in the southern hemisphere. Similarly, the averages of March, April and September, October represented spring equinox and autumn equinox. These equinoctial seasons are common to both hemispheres.

\section{Results}

Figure 2 shows a typical example of ionospheric irregularities on 09 April 2013, a very quiet day with sum of $\mathrm{Kp}=1^{+}$. The irregularities manifested in the form of TEC depletions (panel 1) which are the signature of EPBs, over the (a) northern crest, NC, (b) trough, T and (c) southern crest, SC. The three stations utilized were Sheb ( $7.36^{\circ}$ dip), Addis Ababa $\left(0.16^{\circ}\right.$ dip) and Malindi ( $-12.20^{\circ}$ dip). Irregularities were captured as fluctuations in ROT (panel 2) and increase in ROTI (panels 3) as well as average ROTI (panel 4). They occurred from about 19:30 LT to 02:00 LT, but were dominant during the post sunset to midnight period over the three stations. They were stronger at the crests and weaker at the magnetic equator.

The day-to-day variation of irregularities at (a) NC, (b) T and (c) SC for quiet days of 2013 are presented in Figure 3. The white spaces were due to lack of data and exclusion of days 
with $\mathrm{Kp}>3$. The black vertical lines at 24:00 LT indicate the local midnight. Generally, the pattern of irregularities occurrence showed predominance during quiet days 70 to 150 and 210 to 290 with a pronounced hemispherical asymmetry over all stations. Their strength decreased from SC to NC, then $\mathrm{T}$. The time of occurrence in the post sunset varied within 19:30 - 21:00 LT over NC and T, and 20:30 - 22:00 LT over SC. The activity lasted till about 03:00 LT, but was protuberant during post noon to pre-midnight period over all stations. It was observed that ionospheric irregularities occurred earlier from quiet days 70 to 150 and 250 to 290 (September to October) and latter from quiet days 160 to 200 (June to July).

Figure 4 is a zoomed portion of Figure 3 but for the month of July. This was used to closely examine the behavior of irregularities during summer especially in the post midnight period. This month was chosen because it recorded the strongest irregularities over all stations during this season. The white areas represent days without data or days with $\mathrm{Kp}>3$. From this Figure, we could distinguish: (i) irregularities occurring in the post sunset period and decaying before midnight, (ii) irregularities occurring in the postmidnight period (both types are clearly seen at SC) and (iii) irregularities from the dusk-sector extending into the postmidnight period.

Figure 5 shows the monthly variation of ROTI during quiet days at NC (red line), T (green line) and SC (blue line). This Figure was constructed by taking monthly averages of ROTI for all visible satellite every 5 minutes. Overall, January, February and December had ROTI $\leq$ 0.1 TECU whilst those of March, April, September and October had ROTI > 0.5 TECU/min but over the crests. Highest ROTI of 1.39, 0.58 and $1.88 \mathrm{TECU} / \mathrm{min}$ were obtained in April at NC, T and SC, respectively. However, ROTI for SC was higher than that of NC in all months except in November, January and February. Interestingly, ROTI at $\mathrm{T}$ was comparable to that at NC in May - August. In addition, during these months, variations of ROTI in the post sunset period were not too different from those in the postmidnight period. Postmidnight irregularities with ROTI $\geq 0.5 \mathrm{TECU} / \mathrm{min}$ were also observed in April - May; July and November - December but only over SC. Weaker irregularities $(0.26 \leq$ ROTI < 0.5$)$ occurred in March, June and August.

Figure 6 presents monthly variations of the EIA in the post sunset period along longitude $37^{\circ}$ with latitudinal coverage of $\pm 30^{\circ}$. The profile was reconstructed using 15 minutes average of VTEC from 19:00 - 22:00 LT during quiet days only. The red line indicates the mean of all 15 minute VTEC values during this period. From this Figure, the EIA profile was more asymmetric with greater differential extent (farthest crests) during the months of January and November - December. Conversely, the anomaly strength in both hemispheres was greater than $20 \mathrm{TECU} / \mathrm{min}$ in March - April and September - December (Table 3). In addition, the latitudinal position of the northern and southern crests saddled $17^{\circ}-22^{\circ}$ geographic latitude $\left(8.2^{\circ} \mathrm{N}-13.7^{\circ} \mathrm{N}\right.$ magnetic latitude) and $2^{\circ}$ to $-11^{\circ}$ geographic latitude $\left(7.3^{\circ} \mathrm{S}-21.3^{\circ} \mathrm{S}\right.$ magnetic latitude), respectively. It is important to recall that these variations are similar to those presented in Amaechi et al. (2018c) but are more accurate in the present study because of the increase number of stations used and better latitudinal and temporal resolution. The new result is that the position of the trough of the African EIA varies from $2.2^{\circ} \mathrm{S}-3.0^{\circ} \mathrm{N}$ 
magnetic latitude and should not be assumed to be fixed as has been the case in several previous studies. Furthermore, the differential extent between both crest was highest in November - January and least in June - July.

Monthly variations of $\Delta \mathrm{H}$ (blue line) and EEF (green line) sampled at 5 minutes are presented in Figure 7 from January to December 2013. There was no data for $\Delta H$ from October to December. EEF replicates clearly the daytime features of $\Delta H$ with both quantities reaching their maximum value at almost the same time. The correlation coefficient of $r=0.73$ highlights the strength of the relation between both electric fields thus, validates EEF for longitude $37^{\circ}$. In the post sunset period, EEF reached its greatest peak in April $(0.74 \mathrm{mV} / \mathrm{m})$ and October $(0.67 \mathrm{mV} / \mathrm{m})$ and lowest from May to August $(0.06-0.15 \mathrm{mV} / \mathrm{m})$.

Monthly variations of percentage irregularities occurrence for (a) post sunset and (b) postmidnight are shown in Figure 8. During post sunset, for NC, T and SC, April had the highest occurrences of irregularities with percentages of $91.67 \%, 75.00 \%$, and $96.43 \%$. This was followed by September with $73.00 \%, 50.00 \%$ and October with $90.00 \%$. December had the least percentage of $3.57 \%, 3.33 \%$ and $3.23 \%$. During postmidnight, $\mathrm{T}$ recorded percentage occurrences lesser than 10\% except in August (14.29\%) and April (10.00\%). NC registered highest occurrences in April (50.00\%) and August (20.00\%) while SC did same in April $(85.71 \%)$ and July (55.17\%). There was no postmidnight irregularity in January February and November - December.

Figure 9 shows seasonal variation of (a) ionospheric irregularities for NC (red line), $\mathrm{T}$ (green line) and SC (blue line), (b) the EIA from 19:00 - 22:00 LT and (c) $\Delta \mathrm{H}$ (blue line) and EEF (green line) during quiet days of year 2013. In Figure 9a, all ROTI values for available satellites were average every 5 minutes. Generally, ROTI was higher over the crests than at the trough in both equinoxes while in summer it was almost the same in NC and SC. In winter however, it barely reached $0.15 \mathrm{TECU} / \mathrm{min}$. There was a pronounced north-south asymmetry in irregularities with SC having the stronger irregularities (higher ROTI). Furthermore, spring equinox had stronger irregularities than autumn equinox over all stations. Also, irregularities decayed before the local midnight in autumn equinox while they extended in the post midnight period in spring equinox and summer. Summer irregularities nonetheless, decayed with a slower and constant rate from post sunset to post midnight as oppose to a consistent and rather sharp decay in spring equinox. From Figure 9b, the overall anomaly profile was more symmetric in both equinoxes with strongest anomaly $(>25.00$ TECU). However, spring equinox had smaller anomaly strength and lesser latitudinal and differential extents than autumn equinox (see Table 3). In winter, the overall shape of the anomaly was more developed in NC than SC while the reverse was the case in summer. Nevertheless, estimated latitudinal and differential extents were greater in winter than summer in both hemispheres (Table 3). Correspondingly, the computed $\triangle \mathrm{TEC}$ in winter was 18.32 and 18.98 TECU as against 4.88 and 13.28 TECU in summer for NC and SC, respectively. From Figure 9c, post sunset peak EEF values of $0.64 \mathrm{mV} / \mathrm{m}$ and $0.59 \mathrm{mV} / \mathrm{m}$ were reached at about 16:33 UT (19:33 LT), in spring equinox and autumn equinox. In winter and summer, the respective EEF peaks were $0.34 \mathrm{mV} / \mathrm{m}$ at 16:10 UT (19:10 LT) and 0.11 $\mathrm{mV} / \mathrm{m}$ at 16:40 UT (19:40 LT). 
From the seasonal profile of meridional wind shown in Figure 10, it was observed that the wind was poleward in both hemispheres from 19:00 - 23:00 LT in winter. Also, in the northern hemisphere it increased from $37 \mathrm{~m} / \mathrm{s}$ in Addis Ababa $\left(0.16^{\circ} \mathrm{dip}\right)$ to $50 \mathrm{~m} / \mathrm{s}$ in Sheb $\left(7.36^{\circ} \mathrm{dip}\right)$ and then $100 \mathrm{~m} / \mathrm{s}$ in Al Wajh $\left(18.73^{\circ} \mathrm{dip}\right)$. In the opposite hemisphere, wind magnitude was approximately $37 \mathrm{~m} / \mathrm{s}$ in Malindi (-12.20 dip) and Tanzania (-16.59 $\mathrm{dip})$. In post midnight, meridional wind reversed to equatorward with stronger magnitude over the southern hemisphere. In summer, the poleward wind barely reached $75 \mathrm{~m} / \mathrm{s}$ in both hemispheres. However, its magnitude decreased from Tanzania to Malindi, then Adis Ababa, Sheb and Al Wajh. The reverse was the case for equatorward wind with its highest magnitudes at Al Wajh and Sheb. From about 23:00 - 02:00 LT, meridional wind reversed to poleward (equatorward) in the southern (northern) hemisphere. Wind patterns were similar in both equinoxes albeit with slightly different magnitudes.

Figure 11 presents seasonal variation of percentage irregularities occurrences in (a) post sunset and (b) postmidnight at NC, T and SC. The striking feature of this figure is the absence of irregularities in winter for postmidnight and the least occurrence for post sunset (12.50\%, 5.60\% and $4.50 \%$ for $\mathrm{NC}, \mathrm{T}$ and SC). Overall, equinoxes had the highest percentage occurrences in the post sunset with spring having more occurrence than autumn for all stations. In postmidnight, percentage irregularities occurrences were highest in spring, then summer and finally autumn over the crests. Over the trough they barely reached $8.00 \%$ over all stations.

\section{Discussion}

EPBs with stronger intensity occurred predominantly in equinoxes then in summer while in winter their occurrence rate and intensity were significantly reduced (Figures 8a and 11a). This seasonal behavior is well explained in terms of the alignment of the solar terminator with the magnetic meridian (Tsunoda, 1985). Over African, this ideal geometric set up occurs during equinox (Burke et al., 2004) when conductivity gradient is enhanced and electric field strong enough to provide the utmost vertical drift needed to lift ionization up hence, creating steeper density gradient, a scenario favorable for the generation of irregularities by the R-T instability in the post sunset ionosphere (Eccles et al., 2015). Stronger post sunset vertical drift (Figure 9c) in conjunction with high background ionization characteristics of equinox season (Figure 9b) were thus, likely mechanisms controlling the observed seasonal behavior of irregularities. This as in line with previous findings the Africa region (e.g., Ackah et al., 2011; Paznukhov et al., 2012; Oladipo \& Schüler, 2013; Akala et al., 2014; Seba \& Gogie, 2015; Mungufeni et al., 2016).

Unlike electric field, the influence of the post sunset EIA on the variation of irregularities has receiver lesser attention in the African sector. Over the Indian sector, it has been suggested that a well-developed anomaly can be taken as a base-level pre-requisite for the development of irregularities (Raghavarao et al., 1988; Rama Rao et al., 1997). From our results, stronger anomaly $(\triangle \mathrm{TEC}>20 \mathrm{TECU})$ corresponded well with higher occurrence of irregularities during equinoxes. On the other hand for anomaly strength within $15-20$ TECU, the largest differential extent (farthest crests) occured in winter which additionally recorded the weakest 
irregularities and least occurrence rate. Interestingly, the considerable summer irregularities occurrence rate coincided with anomaly strength lesser than 15 TECU and related smallest differential extent (closest crests). These results not only highlight the influence of the EIA's morphology (strength and location of crests) on the variability of irregularities, but also suggest that a combination of stronger anomaly and closer crests are favorable conditions for the occurrence of irregularities over Africa. Seba et al. (2018) had shown that mean crest to trough ratio $(\mathrm{CTR}) \geq 1.4$ was a good condition for the occurrence of irregularities over Africa.

It is well known that the location of the crests of the EIA hence, its asymmetry is modulated by transequatorial neutral winds (Paul \& Dasgupta, 2010; Khadka et al., 2018). Modeled values of meridional wind increased poleward from $37 \mathrm{~m} / \mathrm{s}$ to a maximum value of $100 \mathrm{~m} / \mathrm{s}$ in the northern hemisphere while it was about $37 \mathrm{~m} / \mathrm{s}$ in the southern hemisphere in winter. This was consistent with the overall shape of the anomaly which appeared deflected northward and was more developed in the northern hemisphere. Khadka et al. (2018) had stressed on the role of the direction of meridional wind in creating the asymmetry of the EIA in the South American sector. The strong meridional winds pulled the crests farther apart giving rise to the largest differential extent and asymmetry in the crests' position during winter. Such winds are known to created unfavorable condition for the generation of irregularities. According to Maruyama (1988), meridional winds can cause an unequal molecular ion distribution in the conjugate F-region with net increase in the field line integrated conductivity $\sum_{\mathrm{E}, \mathrm{F}}$ thus, a decrease in the R-T growth rate. The presence of the wind and its modulating effect on the asymmetry of the EIA was thus, responsible for the least irregularities occurrences in winter. Zalesak and Huba (1991) and Mendillo et al. (1992) had shown that northward (southward) transequatorial wind will have a stabilizing effect on the instability growth rate along the entire flux tube. Our results are also in line with those of Seba et al. (2018) who found that during winter (summer), the mean meridional wind was northward (southward) in the local post sunset with modelled velocity of $47 \mathrm{~m} / \mathrm{s}(43 \mathrm{~m} / \mathrm{s})$ with a consequent delfection of the anomaly northward (southward) in year 2014. Tesema et al. (2017) confirmed the direction of flow of interhemispheric wind from summer to winter hemispheres and further obtained $r$ meridonal wind speed of 30 to $50 \mathrm{~ms}^{-1}$ poleward during winter in the local evening at Bahir Dar, Ethiopia $\left(11.6^{\circ} \mathrm{N}, 37.4^{\circ} \mathrm{E}\right)$ using an imaging Fabry-Perot Interferometer.

The behavior of irregularities in summer and winter can also be explained in terms of the late time of reversal of PRE at the dip equator. According to Fejer et al. (1999), the later (earlier) time of reversal of the PRE which occurs in the local summer (winter) at the magnetic equator favors (inhibits) the occurrence of irregularities. From modelled values of EEF, the time of the reversal occured earlier in winter $(16: 10 \mathrm{UT}=19: 10 \mathrm{LT})$ and later in summer $(16: 40 \mathrm{UT}=19: 40 \mathrm{LT})$ [Figure 9c]. It is thus, expected that the summer irregularities occurrence rate will be higher than the winter one especially, given that the magnetic equator is in the northern hemisphere in Africa (Figure 1).

Irregularities at the crests and trough were asymmetric in equinoxes with spring having more irregularities than autumn. Correspondingly, the crests were closer to the magnetic equator while the differential extent was smaller and the PRE (captured by variations of EEF) 
stronger in spring than autumn. Contrastingly, the anomaly was stronger in autumn than spring. These results suggested that the location of the crests played a determining role in the equinoctial asymmetry over the African EIA. Modelled wind values showed slight differences in the magnitude of poleward wind in spring and autumn. Seba et al. (2018) had related the difference in wind pattern between March and September 2014 to the differences in ROTI values during these months. They further explained the equinoctial asymmetry in irregularities in terms of background density. They argued that the existence of strong TEC in March will create higher density gradient (Mendillo et al., 1992) that are favorable for the development of plasma density irregularity in March than September. The equinoctial asymmetry in our case has been related to the stronger drift and closer position of the crests in spring.

The latitudinal variation of irregularities revealed stronger irregularities and greater occurrence rate over the crests than at the trough (Figures 9a and 11). This was associated with the high (low) background ionization that is characteristics of the crests (through) especially, during high solar activity. Cervera \& Thomas (2006) had also found peak irregularities activity at the crests and a reduction at the trough in the South-East Asian longitude. This latitudinal feature is clearly in line with the known climatology of scintillations presented in Basu et al. (1980) and Aarons and Basu (1994). One new irregularities feature observed was the similarity in summer irregularities strength and occurrence rates between the northern crest and trough. This puzzling feature might have been related to the smallest latitudinal extent and weakest anomaly in the northern hemisphere. In effect, the northern crest was closest to the magnetic equator with almost similar background ionization as the trough during this season. Another interesting feature is the interhemispheric asymmetry of irregularities over the crests of the anomaly in Africa. This north-south asymmetry was marked by stronger irregularities and more occurrences in the southern crest. This could be traced to the fact that the anomaly was generally stronger in the southern hemisphere (Table 3). The magnitude of the drift in both hemispheres might have also influence the behavior of irregularities over the crests. The plausible role of neutral winds in driving differences in irregularities at the two anomaly regions in the South-East Asian sector had been highlighted by Cervera \& Thomas (2006). These authors suggested that the winds could generate eastward electric field asymmetries with respect to the dip equator. In our case, the asymmetry of the wind with respect to the geomagnetic was pronounced during summer when the north-south asymmetry in irregularities was prominent. Other contributing factors to this north-south asymmetry may have been related to the location of the magnetic equator in the northern hemisphere as well as the involvement of irregularities processes of non-equatorial origin. It is well known that irregularities at the crests often originate from the magnetic equator. However, crests irregularities can be generated locally by seeding mechanism such as gravity waves (Huang \& Kelley, 1996), and neutral wind in the E-region (Yokoyama et al., 2009) and/or may be influenced by polarization electric field related to medium scales traveling ionospheric disturbances (MSTIDs) propagating from the mid-latitudes to the crests of the EIA in both hemispheres (Miller et al., 2009). Mathew et al. (1991) had stressed that in addition to equatorial processes, irregularities at the crest of the Indian anomaly were generated locally or/and 
might have come from mid-latitude. The contribution of MSTIDs and low atmospheric sources capable of influencing irregularities at the crests nevertheless, requires further investigations.

Postmidnight irregularities were found to be essentially weaker in strength with considerable occurrence over the southern crest. Their behavior in equinox suggested that they were residual of the dusk-sector EPBs activity. In summer nonetheless, there was clear evidence of the formation of irregularities in the postmidnight period. Yizengaw et al. (2013) attributed the presence of strong postmidnight irregularities in June solstice to the R-T instability and strong upward drift capable of lifting the F layer. They postulated that the polarization electric field were generated by sporadic $\mathrm{E}$ which often occurs during summer plausibly as a result of dust storms typical of the African sector (Kamra, 1972). This could as well be a plausible explanation for postmidnight summer irregularities observed in this work. It is however, important to note that irregularities reported in the present study were less strong and less frequent than those presented in Yizengaw et al. (2013). This could be an indication that postmidnight irregularities were not necessarily associated with strong upward drift but perhaps were due to the creation of sharp vertical gradients through recombination processes in conjunction with transequatorial neutral wind in the night. The pattern of modelled meridional winds clearly underscores their significance and eventual contribution in shaping the dynamism of the postmidnight ionosphere in summer. Nishioka et al. (2012) had stressed on the generation of weak postmidnight irregularities by processes such as recombination and transequatorial wind that transport plasma along the magnetic field. Akala et al. (2015) also reported on weak postmidnight pockets of irregularities over Africa in summer during the minimum phase of solar cycle 24 .

\section{Conclusion}

The variability of ionospheric irregularities over the African EIA during quiet days of year 2013 has been studied along longitude $35^{\circ} \mathrm{E}$. Emphasis was placed on features such as the contribution of the EIA, the asymmetry in irregularities over the crests as well as post sunset and postmidnight irregularities. Our results show that:

1. The position of the trough of the African EIA varied from $2.2^{\circ} \mathrm{S}-3.0^{\circ} \mathrm{N}$ magnetic latitude and should not be assumed to be fixed as has been the case in several previous studies.

2. Irregularities occurred from 19:30 - 03:00 LT during quiet days of year 2013. The activity started earlier over the northern crest and trough (19:30 LT) and an hour later (20:30 LT) over the southern crest. Correspondingly, the time of occurrence of the post sunset peak in electric field predicted by the EEFM varied within 19:00 - 20:00 LT.

3. The highest occurences were registered in equinoxes when the anomaly was the strongest (> 20 TECU). For anomaly strength lesser than 20 TECU however, the smallest (largest) differential extent of the crests seemed to favor (inhibit) irregularites formation in summer (winter). 
4. The strength and occurrence rate of irregularities at the northern crest and trough was similar in summer. This was associated with the location of the northern crest closer to the magnetic equator during this season.

5. The Equinoctial asymmetry over the crests and trough of the African EIA depended on the location of the crests with respect to the magnetic equator in both hemispheres and on the magnitude of post sunset EEF.

6. Irregularities at the crests of the African EIA do not solely come from the magnetic equator but can be generated locally and/or might originate from mid-latitudes.

7. The north-south asymmetry in irregularities over the crests during quiet periods is presented for the first time over Africa. Generally, the southern crests had the stronger and higher occurrences. This asymmetry depended on the strength of the anomaly in both hemispheres, the northward shift in the location of the magetic equator over Africa as well as the contribution of irregularities mechanism of non equatorial origin.

8. Postmidnight irregularities observed in equinox were essentially an extension of the dusksector EPBs activity. During summer nevertheless, especially in the months of June and July there was a clear secondary resurgence/formation of irregularities. This suggested the existence of a post midnight irregularities mechanism plausibly steeper density gradient associated with nighttime recombination and transequatorial wind in the postmidnight.

For a better understanding of the least studied irregularities features such as their asymmetry over the crests, postmidnight occurrences during summer and the contribution of non equatorial processes to irregularities at the crests, further studies are needed using diverse observational tools in both hemispheres of the African EIA.

\section{Acknowledgments}

GNSS data used in this study were provided by the UNAVCO Facility with support from the National Science Foundation (NSF) and National Aeronautics and Space Administration (NASA). The authors wish to thank the ISGI for making available Kp data as well as E. Yizengaw, E. Zesta, M.B. Moldwin, and the rest of the AMBER and SAMBA teams for their magnetometer data. AMBER is operated by Boston College and funded by NASA. We also thank the Institut de Physique du Globe de Paris (IPGP) which manages the magnetometer at Addis Ababa and distribute its data via Intermagnet as well as the Cooperative Institute for Research in Environmental Sciences (CIRES) team for the real-time PPEFM model. Wind data used in this study were obtained from the HWM14. The data were derived from the pyglow package which is an open-source software available at https: //github.com/timduly4/pyglow/. 


\section{References}

Aarons, J., \& Basu, S. (1994). Ionospheric amplitude and phase fluctuations at the GPS frequencies, in: Proceedings of the Institute of Navigation, Alexandria, Va., USA.

Aarons, J., Mullen, J. P., Whitney, H. E., \& MacKenzie, E. M. (1980). The dynamics of equatorial irregularity patch formation, motion and decay. Journal of Geophysical Research: Space Physics, 85, 139-149. https://doi.org/10.1029/JA085iA01p00139

Aarons, J. (1993). The longitudinal morphology of equatorial F-layer irregularities relevant to their occurrence, Space Science Review, 63, 209-243.

Aarons, J., Mendillo, M., \& Yantosca, R. (1997). GPS phase fluctuations in the equatorial region during sunspot minimum. Radio Science, 32, 1535-1550.

Abdu, M. A. (2012). Equatorial spread F/plasma bubble irregularities under storm time disturbance electric fields. Journal of Atmospheric and Solar Terrestrial Physics, 75-76, 44-56.

Ackah, J.B., Obrou, O. K., Zaka, Z., Mene, M. N., \& Groves, K. (2011). Study of Equatorial Ionospheric Scintillation and TEC characteristics at Solar minimum using GPS-SCINDA data. Sun and Geosphere, 6(1), 27-30.

Akala, A.O., Amaeshi. L. L. N., Doherty, P. H., Groves, K. M., Carrano. C. S., Bridgwood, C.T., Seemala, G.K., \& Somoye, E.O. (2014). Characterization of GNSS scintillations over Lagos, Nigeria during the minimum and ascending phases (2009-2011) of solar cycle 24. Advances in Space Research, 53, 37-47.

Akala A.O, Amaeshi L.L.N, Somoye E.O, Idolor R.O, Okoro E, Doherty P.H, Groves K. M, Carrano C. S, Bridgwood C. T, Baki P, D’ujanga F.M, \& Seemala G. K. (2015). Climatology of GPS amplitude scintillations over equatorial Africa during the minimum and ascending phases of solar cycle 24. Astrophysics and Space Science, 357(17). https://doi.org/10.1007/s10509-015-2292-9

Akala, A.O., Idolor, R., D’Ujanga, F. M., \& Doherty, P. H. (2016). GPS Amplitude Scintillation over Kampala, Uganda, during 2010-2011. Acta Geophysica, 64(5), 1903-1915.

Amaechi, P. O., Oyeyemi, E. O., \& Akala, A. O. (2018a). Geomagnetic storm effects on the occurrences of ionospheric irregularities over the African equatorial/low-latitude region. Advances in Space Research, 61, 2070-2090.

Amaechi, P. O., Oyeyemi, E. O. \& Akala, A. O. (2018b). The Response of African equatorial/

low-latitude ionosphere to 2015 St. Patrick's Day geomagnetic storm. Space Weather, 16(6), 601-618.

Amaechi, P. O., Oyeyemi, E. O., \& Akala, A. O. (2018c). Variability of the African equatorial ionization anomaly (EIA) crests during the year 2013. Canadian Journal of Physics, 97(2), 155-165.

Anderson, D., Anghel, A., Chau, J., \& Veliz, O. (2004). Daytime vertical Ex B drift velocities inferred from ground-based magnetometer observations at low latitudes. Space Weather, 2(11).

Appleton, E.V. (1946). Two Anomalies in the ionosphere. Nature, 157, 691.

Basu, S., Basu, Su., Aarons, J., Mc Clure, J. P., \& Cousins, M. D. (1978). On the coexistence of kilometer- and meter-scale irregularities in the nighttime equatorial $F$ region. Journal 
of Geophysical Research: Space Physics, 83(A9). https://doi.org/10.1029/JA083iA09p04219

Basu, S., Basu, S., Mullen, J. P., \& Bushby, A. (1980). Long-term $1.5 \mathrm{GHz}$ amplitude scintillation measurements at the magnetic equator. Geophysical Research Letters, 7(4), 259-262.

Basu, S., Kudeki, E., Basu, Su., Valladares, C. E., Weber, E. J., Zengingonul, H. P., et al. (1996). Scintillations, plasma drifts, and neutral winds in the equatorial ionosphere after sunset. Journal of Geophysical Research: Space Physics, 101(A12), 26,795-26,809.

Blewitt, G. (1990). An Automatic editing algorithm for GPS data. Geophysical Research Letters, 17 (2), 199-202.

Burke, W. J., Gentile, L. C., Huang, C. Y., Valladares, C. E., \& Su, S. Y. (2004). Longitudinal variability of equatorial plasma bubbles observed by DMSP and ROCSAT1. Journal of Geophysical Research: Space Physics, 109, A12301. https://doi.10.1029/2004JA010583

Cervera, M. A., \& Thomas, R. M. (2006). Latitudinal and temporal variation of equatorial ionospheric irregularities determined from GPS scintillation observations. Annales Geophysicae, 24 (12), 3329-3341.

Chartier, A. T., Makela, J. J., Liu, H., Bust, G. S., \& Noto, J. (2015). Modeled and observed equatorial thermospheric winds and temperatures. Journal of Geophysical Research: Space Physics, 120, 5832-5844, doi:10.1002/2014JA020921

Chu, F-D., Chen, W-S., \& Lee, C-C. (2015). An Investigation of Equatorial Ionospheric Irregularities under Solar Maximum in the 24th Solar Cycle in Middle and East Africa using GPS. PIERS Proceedings, Prague, Czech Republic, July 6-9.

Drob, D. P., Emmert, J. T., Meriwether, J. W., Makela, J. J., Doornbos, E., Conde, M., et al. (2015). An update to the Horizontal Wind Model (HWM): The quiet time thermosphere. Earth and Space Science, 2, 301-319. https://doi.org/10.1002/2014EA000089

D'ujanga, F.M., \& Taabu, S.D. (2014). Study on the occurrence characteristics of VHF and L band ionospheric scintillation over East Africa. Indian Journal of Radio and Space Physics, 43, 263-273.

Eccles, J. V., St. Maurice, J. P., \& Schunk, R. W. (2015). Mechanisms underlying the prereversal enhancement of the vertical plasma drift in the low-latitude ionosphere. Journal of Geophysical Research: Space Physics, 120, 4950-4970.

Estey, L. H., \& Meertens, C. M. (1999). TEQC: The Multi-Purpose Toolkit for GPS/ GLONASS Data. GPS Solutions, 3 (1), 42-49.

Farley, D. T., Bonelli, E., Fejer, B. G., \& Larsen, M. F. (1986). The prereversal enhancement of the zonal electric field in the equatorial ionosphere. Journal of Geophysical Research: Space Physics, 91, 13723-13728.

Fejer, B. J., Scherliess, L., \& de Paula, E. R. (1999). Effects of the vertical plasma drift velocity on the generation and evolution of equatorial spread F. Journal of Geophysical Research: Space Physics, 104 (A9), 19859 - 19,869.

Fejer, B. G., Jensen, J. W., \& Su, S. Y. (2008). Quiet time equatorial F region vertical plasma drift model derived from ROCSAT-1 observations. Journal of Geophysical Research: Space Physics, 113, A05304. 
Habarulema, J. B., Yizengaw, E., Katamzi-Joseph, Z. T., Moldwin, M. B., \& Buchert, S. (2017). Storm time global observations of large-scale TIDs from ground-based and in situ satellite measurements. Journal of Geophysical Research: Space Physics, 123, 711724. https://doi.org/10.1002/2017JA024510

Haerendel, G. (1973). Theory of equatorial spread F, report. Max-Planck Institute for Physics and Astrophysics, Garching, Germany.

Hansen, A., Blanch, J., \& Walter, T. (2000). Ionospheric correction analysis for WAAS Quiet and stormy. ION GPS, Salt Lake City, Utah, September 19-22, 634-642.

Heelis, R. A. (2004). Electrodynamics in the low and middle latitude ionosphere: a tutorial. Journal of Atmospheric and Solar Terrestrial Physics, 66, 825-838.

Hei, M. A., Heelis, R. A., \& McClure, J. P. (2005). Seasonal and longitudinal variation of large-scale topside equatorial plasma depletions. Journal of Geophysical Research: Space Physics, 110, A12315. https://doi.10.1029/2005JA011153

Huang C. S., \& Kelley, M. C. (1996). Nonlinear evolution of equatorial spread F: 1. On the role of plasma instabilities and spatial resonance associated with gravity wave seeding. Journal of Geophysical Research: Space Physics, 101, 283-292.

Huang, C., Burke, W., Machuzak, J., Gentile, L., \& Sultan, P. (2001). DMSP observations of equatorial plasma bubbles in the topside ionosphere near solar maximum, Journal of Geophysical Research: Space Physics, 106(A5) 8131-8142. https://doi.org/ 10.1029/2000JA000319

Huang, C. Y., Burke, W. J., Machuzak, J. S., Gentile, L. C., \& Sultan, P. J. (2002). Equatorial plasma bubbles observed by DMSP satellites during a full solar cycle: toward a global climatology. Journal of Geophysical Research: Space Physics, 107(A12), 1434-14.

Kamra, A. K. (1972). Measurements of the electrical properties of dust storms. Journal of Geophysical Research: Space Physics, 77(30), 5856-5869. https://doi.org/10.1029 /JC077i030p05856

Kaab, M., Benkhaldoun, Z., Fisher, D. J., Harding, B., Bounhir, A., Makela, J. J., et al. (2017). Climatology of thermospheric neutral winds over Oukaïmeden Observatory in Morocco. Annales Geophysicae. 35(1), 161-170.

Khadka, S. M., Valladares, C. E., Sheehan, R., \& Gerrard, A. J. (2018). Effects of electric field

and neutral wind on the asymmetry of equatorial ionization anomaly. AGU Space weather,

https://doi.org/10.1029/2017RS006428

Kelley, M. C. (1989). Ionospheric Radio. Peter Peregrinus Ltd. London.

Kelley, M. C., \& McClure, J. P. (1981). Equatorial spread-F: A review of recent experimental results. Journal of Atmospheric and Terrestrial Physics, 43, 5, 427- 435.

Makela, J. J., Ledvina, B. M., Kelley, M. C., \& Kintner, P. M. (2004). Analysis of the seasonal variations of equatorial plasma bubble occurrence observed from Haleakala, Hawaii, Annales Geophysicae, 22, 3109-3121. htpps://doi/10.5194/angeo-22-3109-2004

Mannucci, A. J.,Wilson, B. D., \& Edwards, C. D. (1993). A new method for monitoring the earth's ionosphere total electron content using the GPS global network. Proceedings of ION GPS-93, Institute of Navigation, 1323-1332. 
Mathew, B., Pathan, B. M., Iyer, K. N., \& Rao, D. R. K. (1991). Comparative study of scintillations at the magnetic equator and at the crest region of the equatorial anomaly in Indian zone. Proceedings of the Indian Academy of Sciences-Earth and Planetary Sciences, 100(4), 331-340.

Maruyama, T., \& Matuura, N. (1984). Longitudinal variability of annual changes in activity of

equatorial spread F and plasma bubbles. Journal of Geophysical Research, 39, 1090310912.

Maruyama, T. (1988). A diagnostic model for equatorial spread F, Model description and application to electric field and neutral wind effects. Journal of Geophysical Research: Space Physics, 93 (14), 611. https://doi.org/10.1029/JA093iA12p14611

Mendillo, M., Baumgardner, J., Pi, X., \& Sultan, P.J. (1992). Onset conditions for equatorial spread F. Journal of Geophysical Research: Space Physics, 97(A9), 13865-13876. https://doi.org/10.1029/92JA00647

Mendillo, M., Lin, B., \& Aarons, J. (2000). The application of GPS observations to equatorial Aeronomy. Radio Science, 35, 885-904.

Miller, E. S, Makela J. J., \& Kelley, M. C. (2009). Seeding of equatorial plasma depletions by polarization electric fields from middle latitudes: experimental evidence. Geophysical Research Letters, 36:L18105. https://doi.org/10.1029/2009GL039695

Mungufeni, P., Habarulema, J. B., \& Jurua, E. (2016). Trends of ionospheric irregularities over

African low latitude region during quiet geomagnetic conditions. Journal of Atmospheric and Solar Terrestrial Physics, 138, 261-267.

Namba, S., \& Maeda, K.-I. (1939). Radio Wave Propagation, 86 pp., Corona, Tokyo.

Ngwira, C. M., Seemala, G. K., \& Habarulema, J. B. (2013). Simultaneous observations of ionospheric irregularities in the African low latitude region. Journal of Atmospheric and Solar Terrestrial Physics, 97, 50-57.

Nishioka, M., Otsuka, Y., Shiokawa, K., Tsugawa, T., Effendy, S. P., Nagatsuma, T., \& Murata, K. T. (2012). On post-midnight field-aligned irregularities observed with a 30.8$\mathrm{MHz}$ radar at a low latitude: comparison with F-layer altitude near the geomagnetic equator. Journal of Geophysical Research: Space Physics, 117:A08337. https://doi.org/10.1029/2012JA017692

Link, R. \& Cogger, L. (1988). A reexamination of the OI 6300-A nightglow. Journal of Geophysical Research: Space Physics, 9883-9892, doi:10.1029/JA093iA09p09883

Oladipo, O.A., \& Schuler, T. (2013). Equatorial ionospheric irregularities using GPS TEC derived index. Journal of Atmospheric and Solar Terrestrial Physics, 92, 78-82. https://doi.org/10.1016/j.jastp.2012.09.019

Oladipo, O. A., Adeniyi, J. O., Olawepo, A. O., \& Doherty, P. H. (2014). Large-scale ionospheric irregularities occurrence at Ilorin, Nigeria. Space Weather, 12, 300-305.

Ossakow, S. L. (1981). Spread-F theories- A review. Journal of Atmospheric and Terrestrial Physics, 43(5/6), 437- 452.

Otsuka, Y., Shiokawa, K., \& Ogawa, T. (2006). Equatorial ionospheric scintillations and zonal irregularity drifts observed with closely spaced GPS receivers in Indonesia. Journal of the Meteorological Society of Japan, 84A, 343-351. 
Paul, A., \& DasGupta, A. (2010). Characteristics of the equatorial ionization anomaly in relation to the day-to-day variability of ionospheric irregularities around the post sunset period. Radio Science, 45, RS6001.

Paznukhov, V., Carrano, V., Doherty, C. S., Groves, P. H., Caton, K. M., Valladares, R. G., C. E., et al. (2012). Equatorial plasma bubbles and L-band scintillations in Africa during solar minimum. Annales Geophysicae, 30, 675-682.

Pi, X., Mannucci, A. J., Lindqwister, U. J., \& Ho, C. M. (1997). Monitoring of global ionospheric irregularities using the worldwide GPS network. Geophysical Research Letters, 24 (18), 2283-2286.

Rabiu, A. B., Mamukuyomi, A. I., \& Joshua, E. O. (2007). Variability of equatorial ionosphere inferred from geomagnetic field measurements. Bulletin of the Astronomical Society of India, 35, 607-618.

Raghavarao, R., Nageswararao, M., Sastri, J. H., Vyas, G. D., \& Sriramarao, M. (1988). Role of equatorial ionization anomaly in the initiation of equatorial spread F. Journal of Geophysical Research: Space Physics, 93(A6), 5959-5964.

https://doi.org/10.1029/JA093iA06p05959

Rama Rao, P. V. S., Jayachandran, P. T., \& Ram, P. S. (1997). Ionospheric irregularities: The role of the equatorial ionization anomaly. Radio Science, 32(4), 1551-1557.

Rama Rao, P. V. S., Niranjan, K., Prasad, D.S.V.V.D., Gopi, S., K., \& Uma, G. (2006). On the validity of the ionospheric pierce point (IPP) altitude of $350 \mathrm{~km}$ in the Indian equatorial and low-latitude sector. Annales. Geophysicae, 24, 2159-2168.

Seba, E. B., \& Gogie, T. K. (2015). Characterization of ionospheric scintillation at a geomagnetic equatorial region station. Advances in Space Research, 56(10), 2057-2063.

Seba, E. B., Nigussie, M., \& Moldwin, M. B. (2018). The relationship between equatorial ionization anomaly and nighttime equatorial spread $\mathrm{F}$ in East Africa. Advances in Space Research, 62(7), 1737-1752.

Seemala, G., \& Delay, S. B. (2010). GNSS TEC data processing. $2^{\text {nd }}$ Workshop on Satellite Navigation Science and Technology for Africa, Trieste, 6-24 April 2010.

Tesema, F., Mesquita, R., Meriwether, J., Damtie, B., Nigussie, M., Makela, J., et al. (2017). New results on equatorial thermospheric winds and temperatures from Ethiopia, Africa. Annales Geophysicae, 35(2), 333-344.

Tsunoda, R. T. (1985). Control of the seasonal and longitudinal occurrence of equatorial scintillations by the longitudinal gradient in integrated E region Pedersen conductivity. Journal of Geophysical Research: Space Physics, 90 (A1), 447-456. https://doi.org/10.1029/ JA090iA01p00447

Valladares, C. E., Villalobos, J., Hei, M. A., Sheehan, R., Basu, Su., Mackenzie, E., et al. (2009). Simultaneous observation of travelling ionospheric disturbance in the Northern and Southern hemispheres. Annales Geophysicae, 27, 1501-1508.

Vestine, E. (1947). The geomagnetic field, its description and analysis. Carnegie Institute, Washington DC.

Wanninger, L. (1993). Effects of the Equatorial Ionosphere on GPS. GPS World, 4(7), 48-54.

Yizengaw, E., Moldwin, M. B., Sahai, Y., \& de Jesus, R. (2009). Strong postmidnight equatorial ionospheric anomaly observations during magnetically quiet periods. Journal 
of Geophysical Research: Space Physics, 114(A12).

https://doi.org/10.1029/2009JA014603

Yizengaw, E., Retterer, J., Pacheco, E. E., Roddy, P., Groves, K., Caton, R., \& Baki, P. (2013). Postmidnight bubbles and scintillations in the quiet-time June solstice. Geophysical Research Letters, 40(21), 5592-5597.

Yizengaw, E., Moldwin, M. B., Zesta, E., Biouele, C. M., Damtie, B., Mebrahtu, A., et al. (2014). The longitudinal variability of equatorial electrojet and vertical drift velocity in the African and American sectors, Annales Geophysicae, 32, 231-238. https://doi.org/10.5194/angeo-32-231-2014

Yizengaw, E., \& Groves, K. M. (2018). Longitudinal and Seasonal Variability of Equatorial Ionospheric Irregularities and Electrodynamics, Space Weather, 16(8), 946-968, https://doi.org/10.1029/2018SW001980

Yokoyama, T., Hysell, D. L., Otsuka, Y., \& Yamamoto, M. (2009). Three-dimensional simulation of the coupled Perkins and Es-layer instabilities in the nighttime midlatitude ionosphere. Journal of Geophysical Research: Space Physics, 114(A3). https:// doi.org/10.1029/2008JA013789

Zalesak, S. T., Ossakow, S. L., \& Chaturvedi, P. K. (1982). Non linear equatorial spread-F: The effect of neutral winds and background Pederson conductivity, Journal of Geophysical Research: Space Physics, 151. https://doi.org/10.1029/JA087iA01p00151

Zalesak, S. T., \& Huba, J. D. (1991). Effect of meridional winds on the development of equatorial spread F. Eos, Transactions American Geophysical Union, 72, 211. 


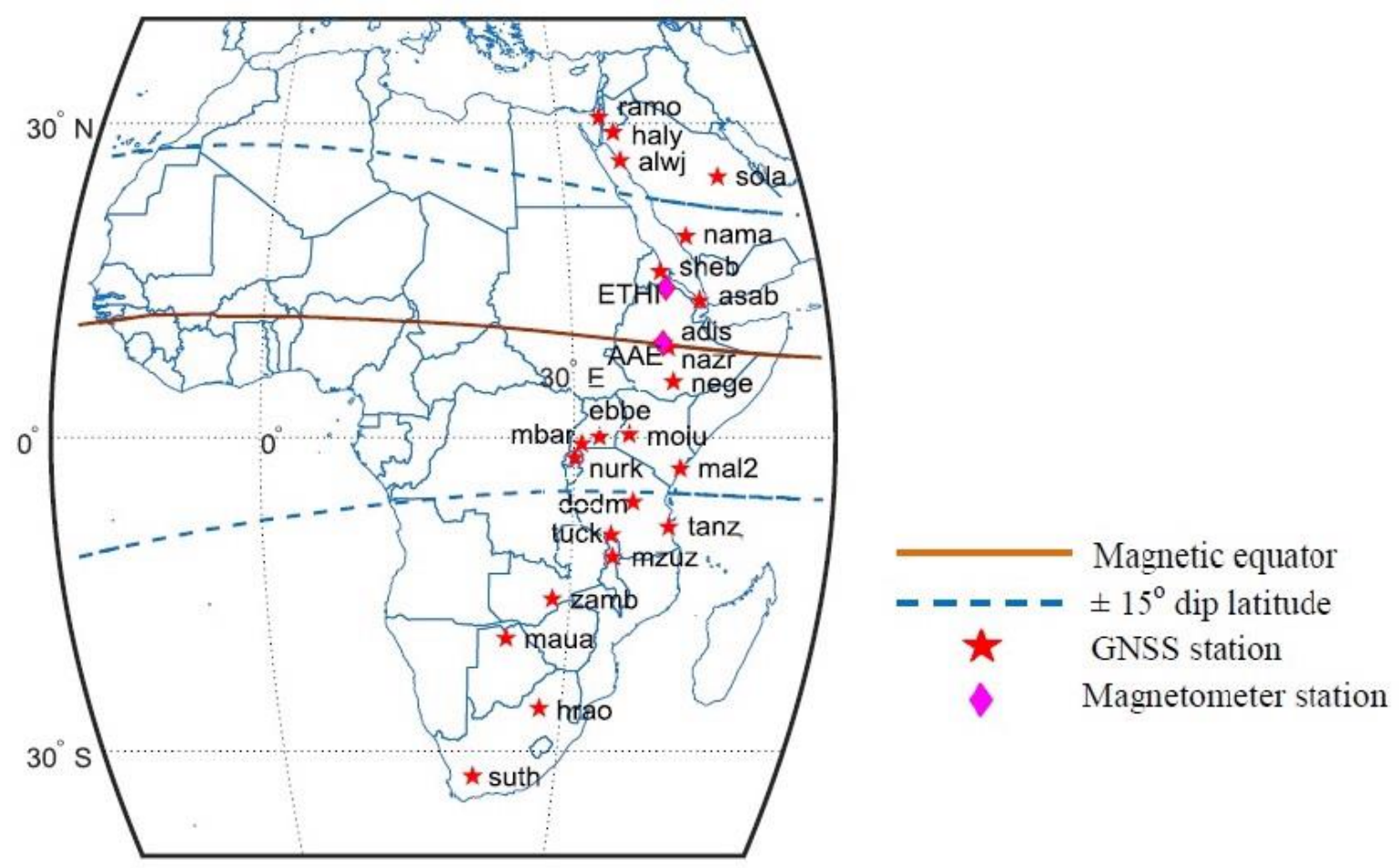

Figure 1. Geographic location of the stations.

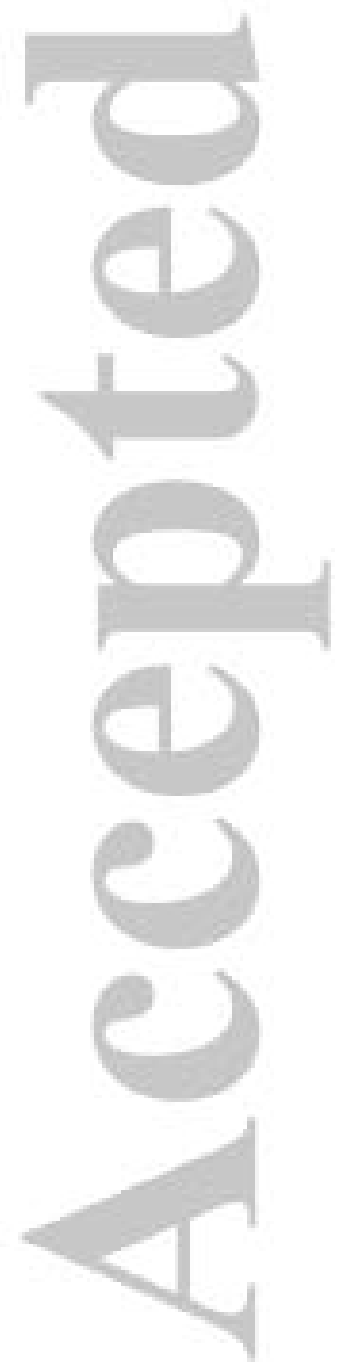




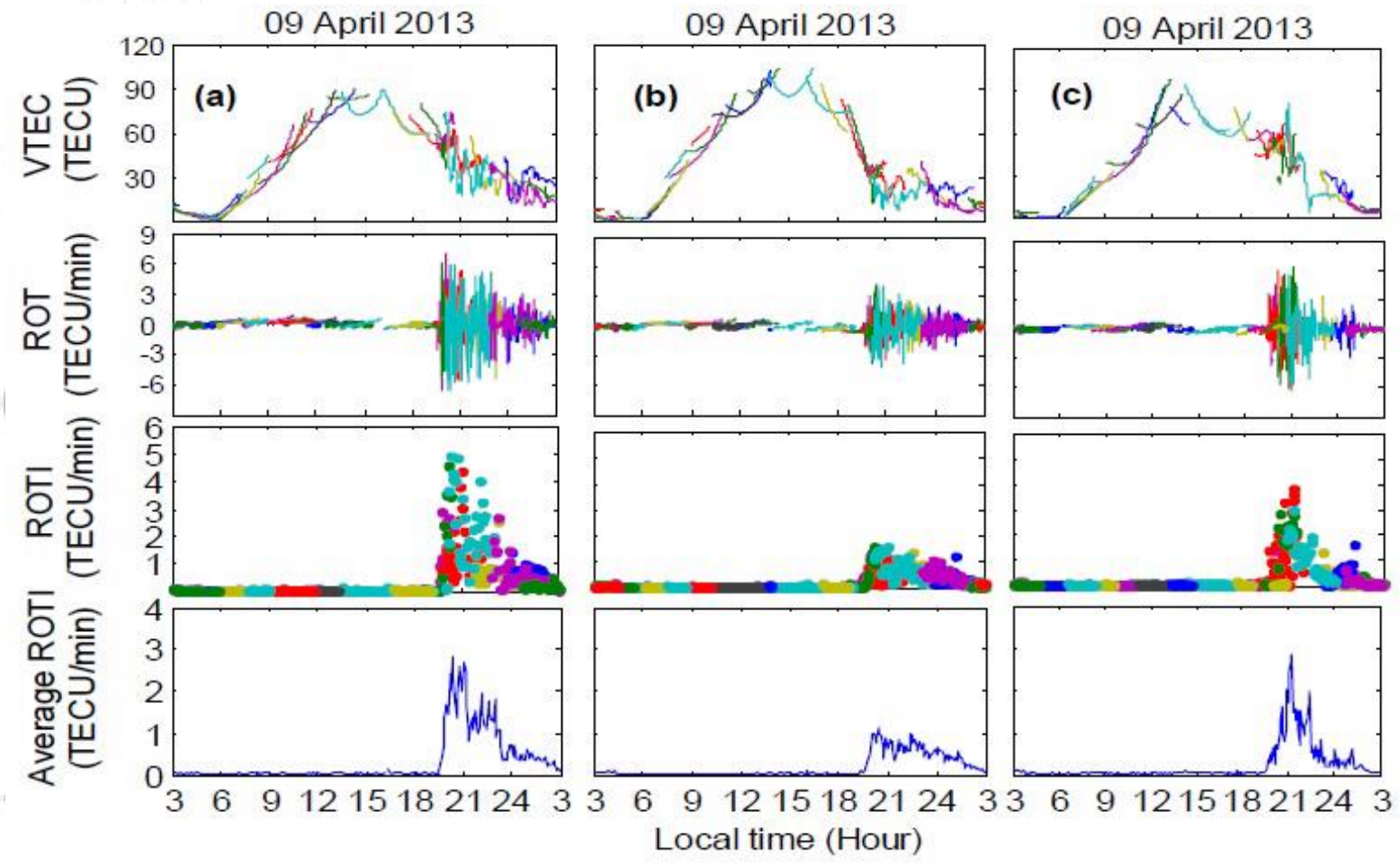

Figure 2. Typical example of ionospheric irregularities on 9th April 2013 over the (a) northern crest, (b) Trough and (c) southern crest. From top to bottom VTEC, ROT, ROTI and average ROTI (ROTI $\left.{ }_{\mathrm{AVE}}\right)$. 
(a) Northern crest

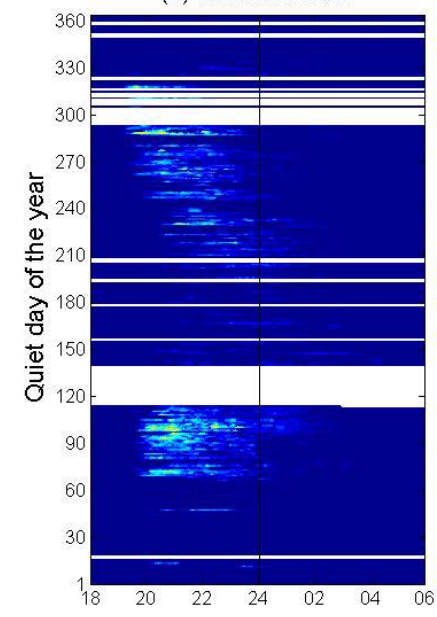

(b) Trough

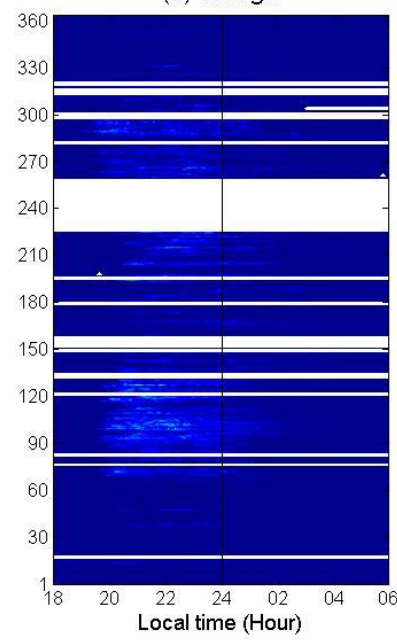

(c) Southern crest

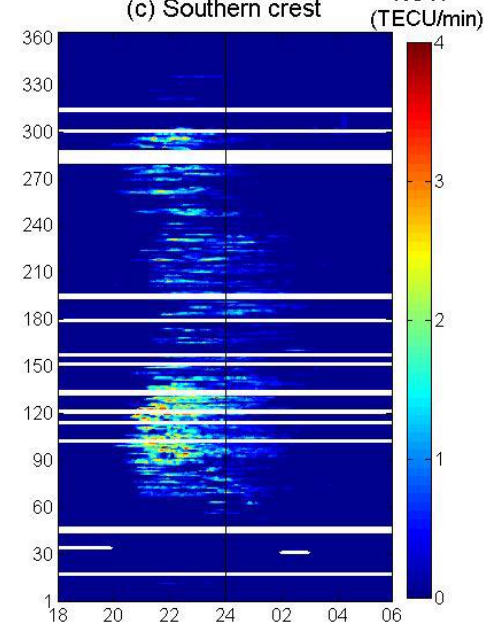

Figure 3. Day-to-day variation of irregularities over stations in the (a) northern crest, (b) trough and (c) southern crest during quiet days of the year 2013 from 18:00-06:00 LT.

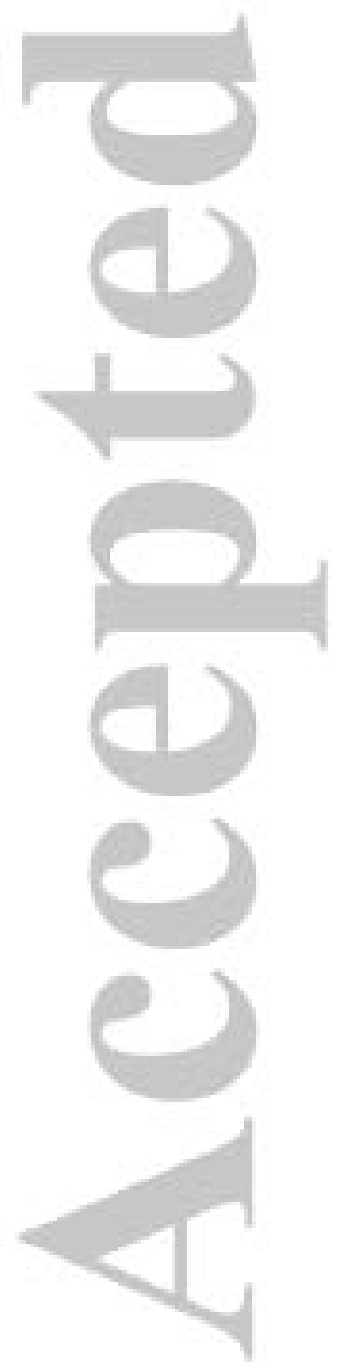




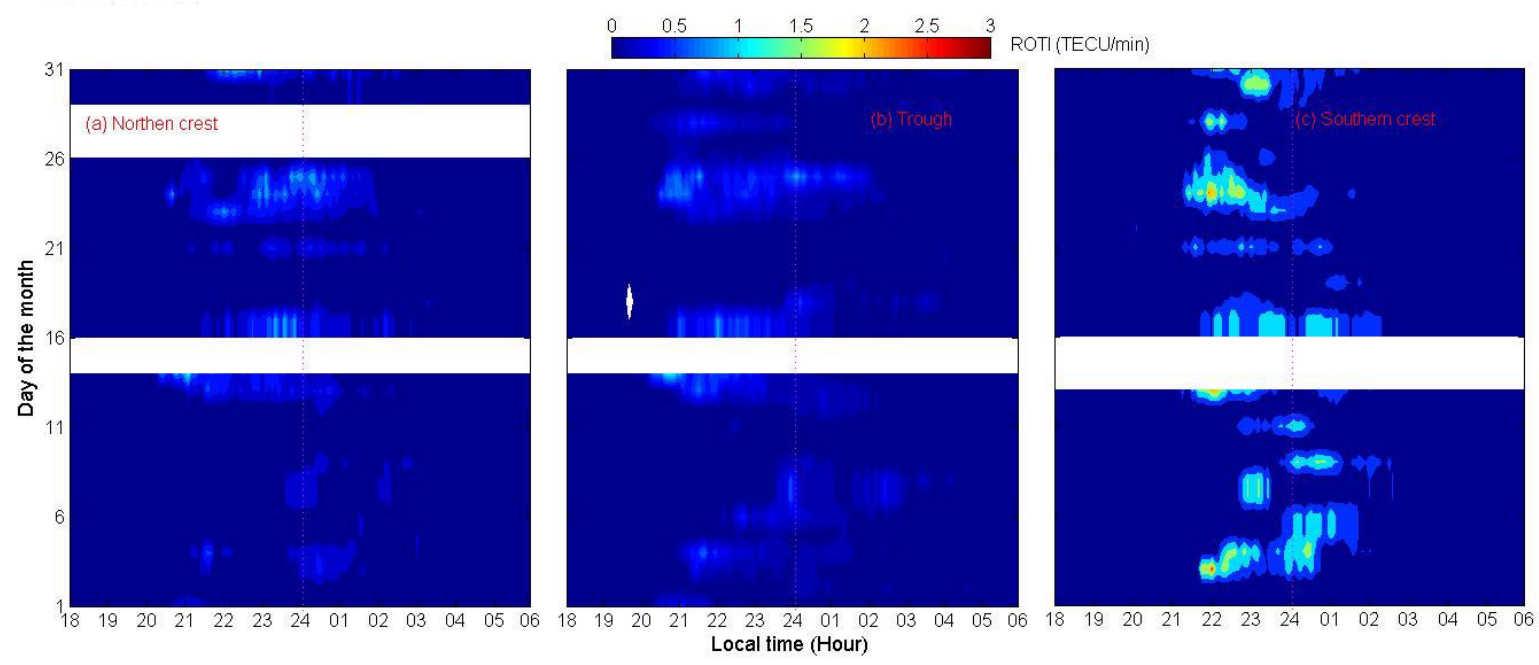

Figure 4. Day-to-day variability of irregularities during quiet days in July 2013 at (a) Northern crest (b) Trough and (c) Southern crest. The white areas represent either days without data or days that were not quiet. 

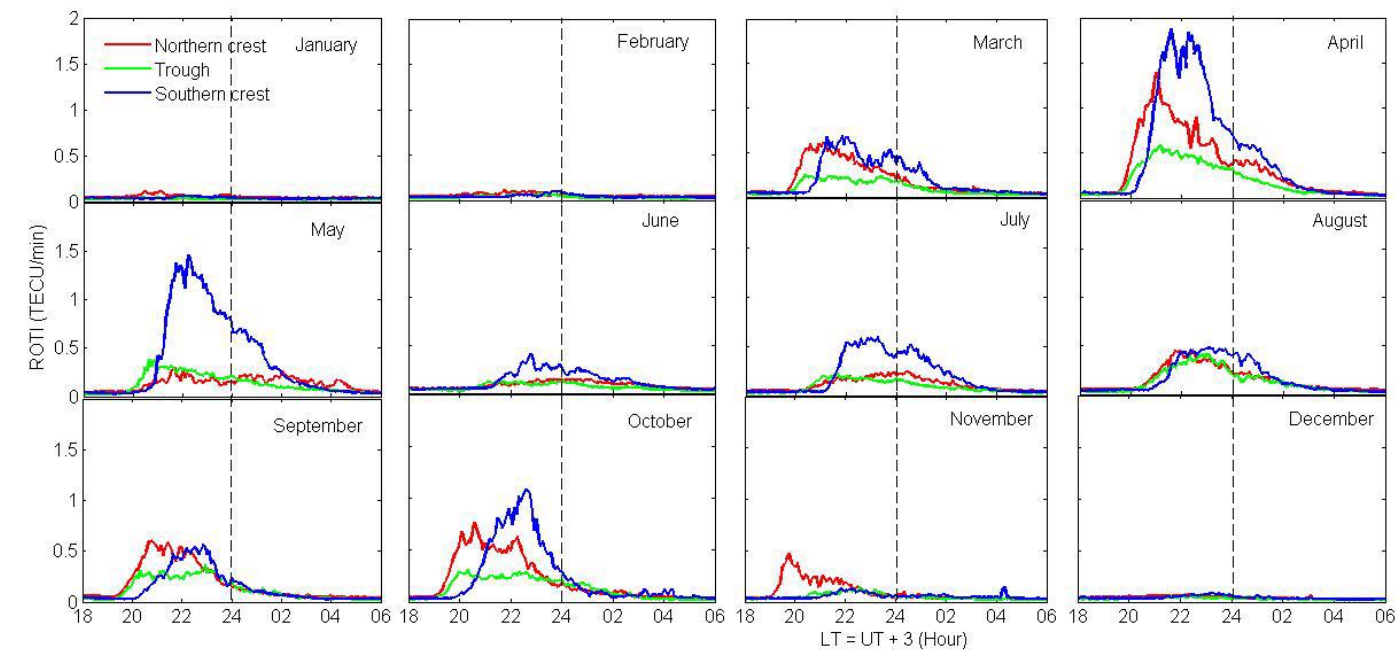

Figure 5. Monthly mean variations of quiet time irregularities over the northern crest (red line), trough (green line) and crest (blue line) in 2013. 

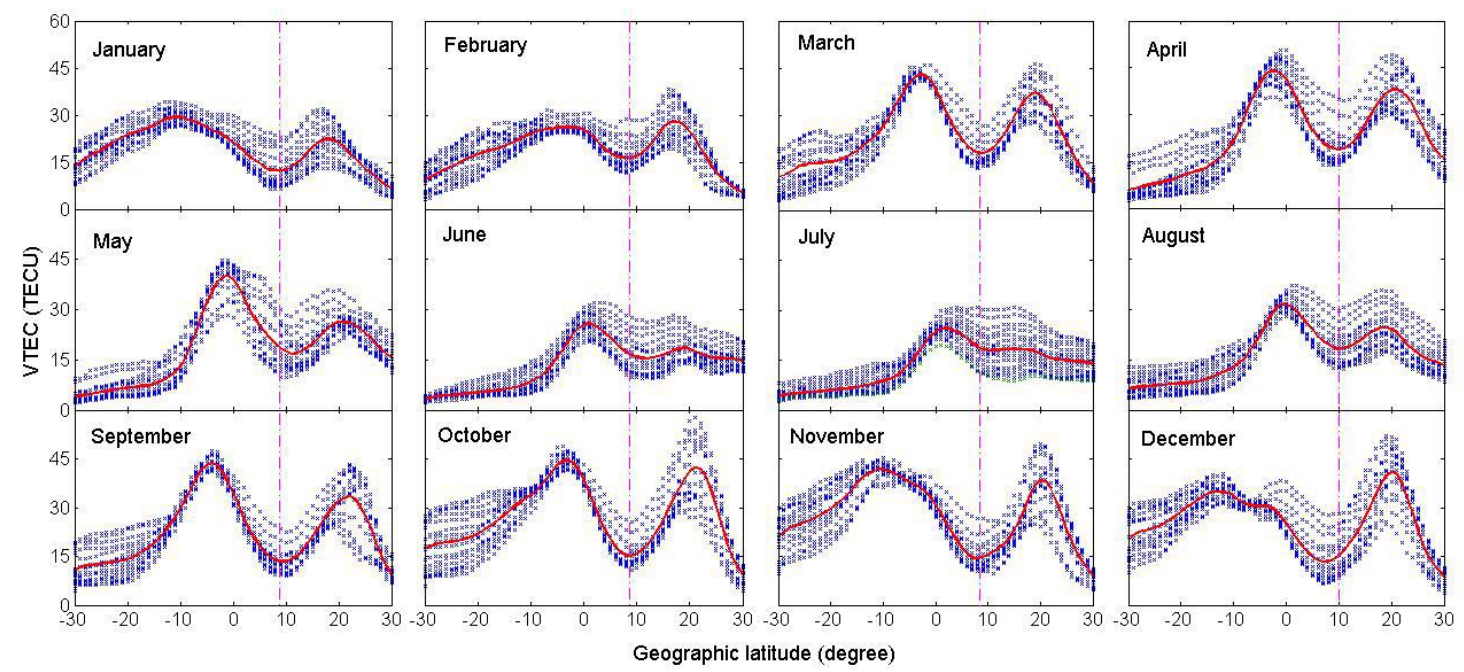

Figure 6. Monthly variations of the EIA in the post sunset period from $19-22$ LT during quiet days of 2013. The red line indicates the mean of VTEC during this period. 


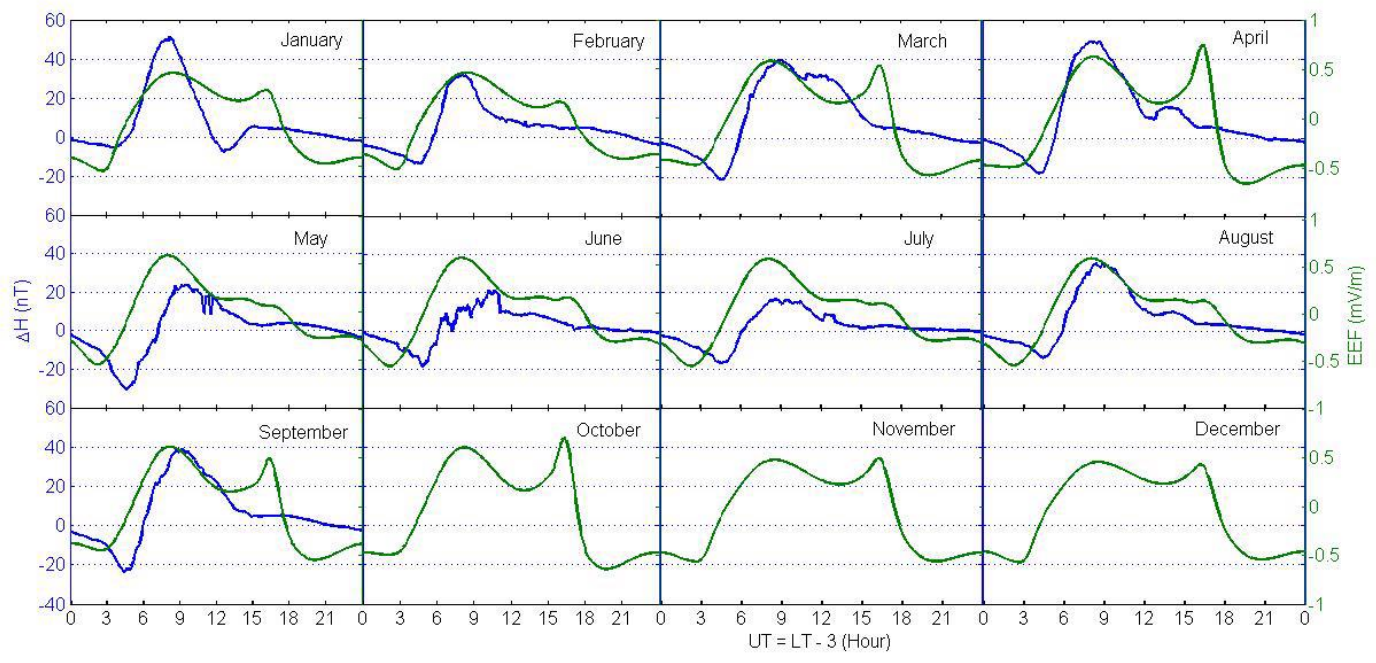

Figure 7. Monthly mean diurnal variation of $\Delta \mathrm{H}$ (red curve) and EEF (blue curve) in year 2013. There was no $\Delta H$ data from October to December. 


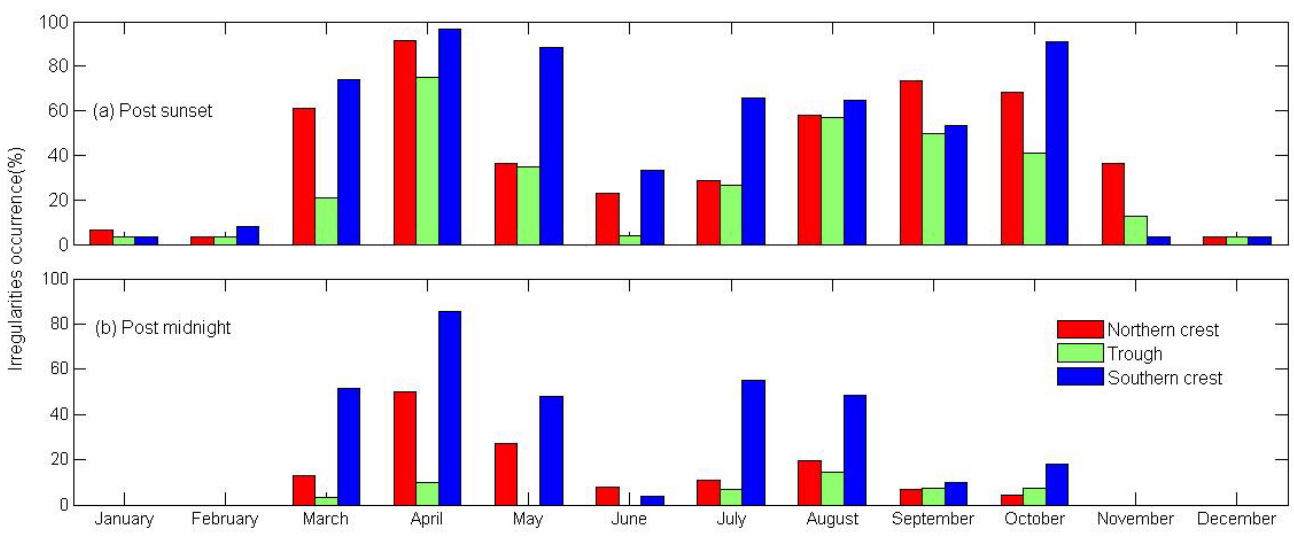

Figure 8. Monthly percentage irregularities occurrences for (a) Post sunset and (b) Post midnight over the northern crest (red), the trough (green) and the southern crest (blue). 

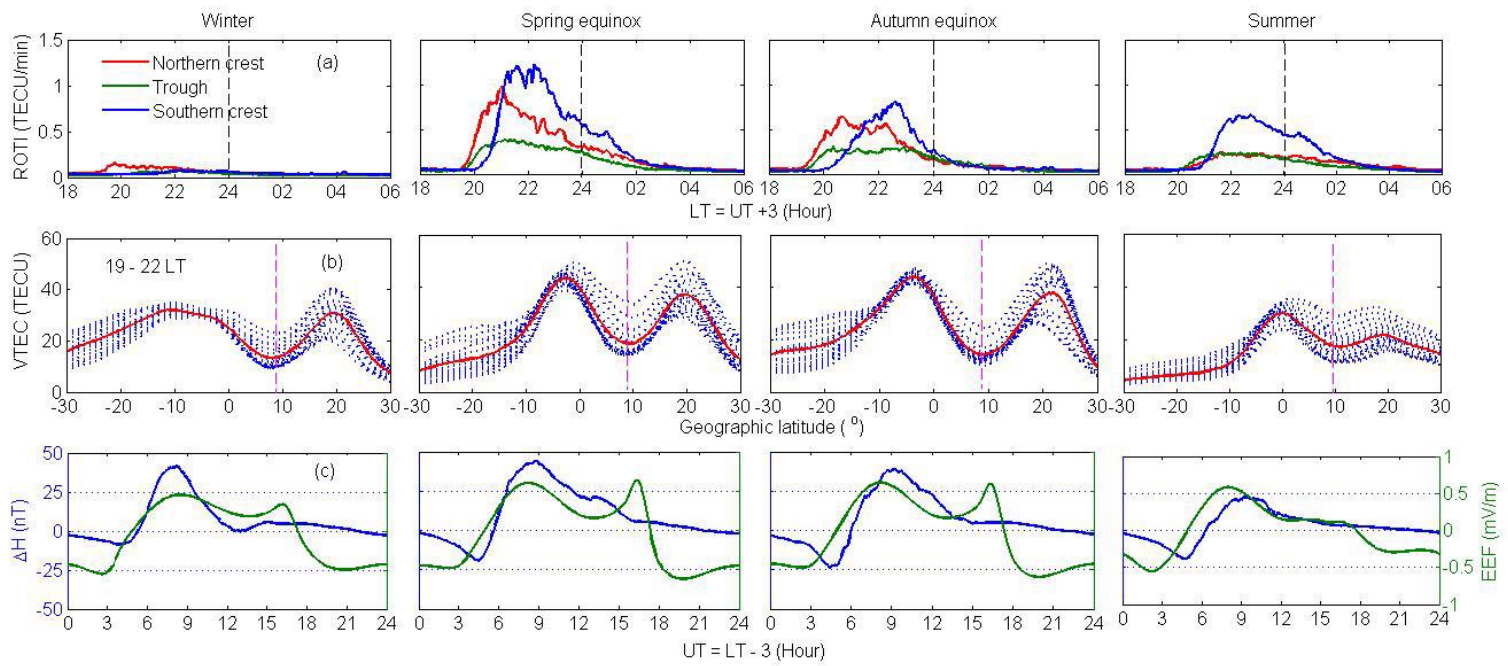

Figure 9. (a) Seasonal variations of (a) irregularities for northern crest (red line), trough (green line) and southern crest (blue line), (b) EIA variation from 19-22 LT and (c) $\Delta \mathrm{H}$ and EEF for quiet days of year 2013. The red line in panel 2 is the mean of all VTEC for the period. Fig.8a was obtained by taken the mean of all ROTI in the season during quiet period.

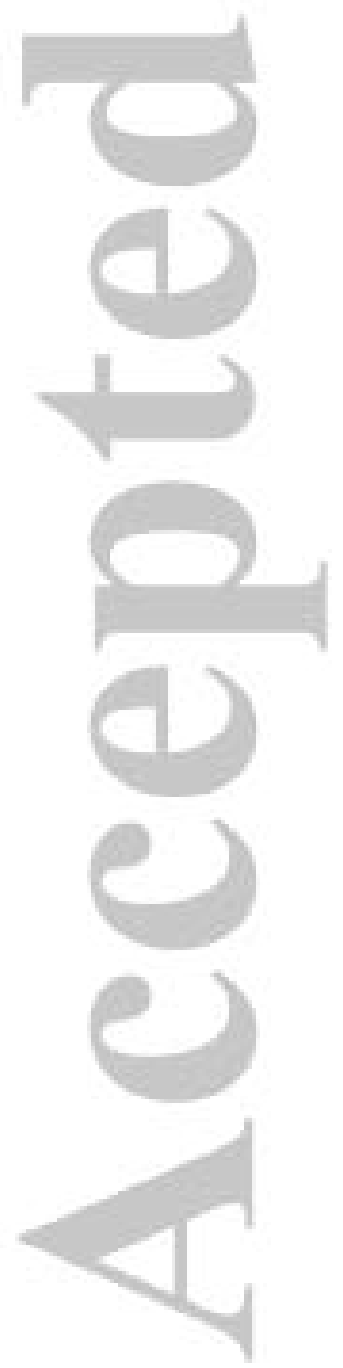


alwj, mag lat: $18.73^{*}$

sheb, mag lat: $07.36^{\text {* }}$

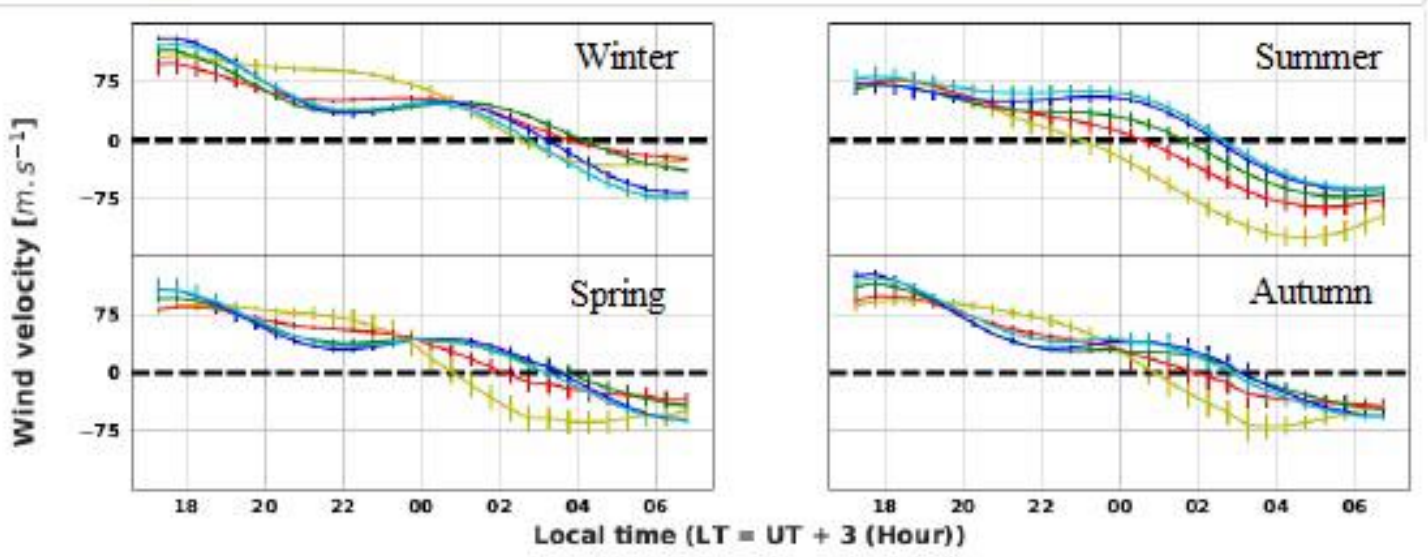

Figure 10. Seasonal variation of meridional wind predicted by the HWM14 model. Positive values are northward. 

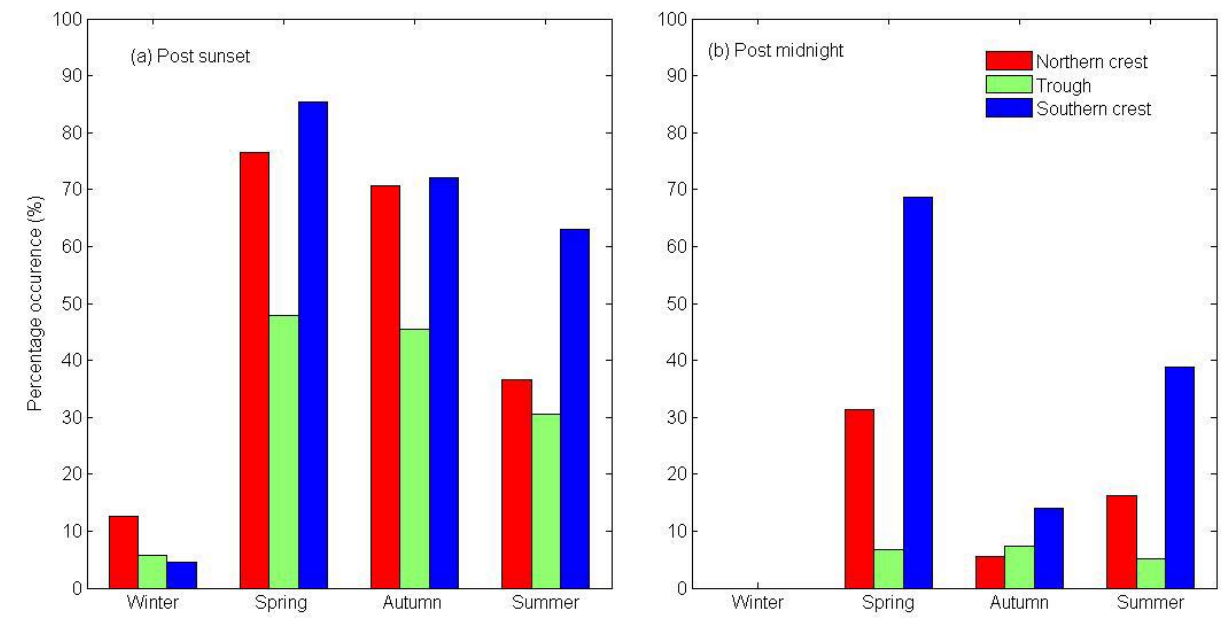

Figure 11. Seasonal variations of percentage irregularities occurrences during (a) post sunset and (b) post midnight for year 2013. 
Table 1: Geographic location of the GNSS and magnetometer stations

\begin{tabular}{|c|c|c|c|c|c|}
\hline \multirow[t]{2}{*}{ Station name / Country } & \multirow{2}{*}{$\begin{array}{l}\text { Station } \\
\text { code }\end{array}$} & \multicolumn{2}{|c|}{ Geographic } & \multicolumn{2}{|c|}{ Magnetic } \\
\hline & & Latitude & Longitude & Latitude & Longitude \\
\hline & \multicolumn{5}{|c|}{ GNSS } \\
\hline Mitzpe Ramon & ramo & $30.61^{\circ} \mathrm{N}$ & $34.80^{\circ} \mathrm{E}$ & $23.38^{\circ} \mathrm{N}$ & $106.30^{\circ} \mathrm{E}$ \\
\hline Halat Ammar, Saudi Arabia & haly & $29.16^{\circ} \mathrm{N}$ & $36.07^{\circ} \mathrm{E}$ & $21.87^{\circ} \mathrm{N}$ & $107.53^{\circ} \mathrm{E}$ \\
\hline Al Wajh, Saudi Arabia & alwj & $26.46^{\circ} \mathrm{N}$ & $36.38^{\circ} \mathrm{E}$ & $18.73^{\circ} \mathrm{N}$ & $107.79^{\circ} \mathrm{E}$ \\
\hline Sola Village, Saudi Arabia & sola & $24.91^{\circ} \mathrm{N}$ & $46.40^{\circ} \mathrm{E}$ & $18.43^{\circ} \mathrm{N}$ & $118.05^{\circ} \mathrm{E}$ \\
\hline Nama, Saudi Arabia & nama & $19.21^{\circ} \mathrm{N}$ & $42.05^{\circ} \mathrm{E}$ & $11.49^{\circ} \mathrm{N}$ & $113.61^{\circ} \mathrm{E}$ \\
\hline Sheb, Eritrea & sheb & $15.85^{\circ} \mathrm{N}$ & $39.05^{\circ} \mathrm{E}$ & $7.36^{\circ} \mathrm{N}$ & $110.60^{\circ} \mathrm{E}$ \\
\hline Asab, Eritrea & asab & $13.06^{\circ} \mathrm{N}$ & $42.65^{\circ} \mathrm{E}$ & $4.91^{\circ} \mathrm{N}$ & $114.34^{\circ} \mathrm{E}$ \\
\hline Addis Ababa, Ethiopia & adis & $9.03^{\circ} \mathrm{N}$ & $38.77^{\circ} \mathrm{E}$ & $0.16^{\circ} \mathrm{N}$ & $110.47^{\circ} \mathrm{E}$ \\
\hline Nazret, Ethiopia & nazr & $8.57^{\circ} \mathrm{N}$ & $39.29^{\circ} \mathrm{E}$ & $0.25^{\circ} \mathrm{S}$ & $111.01^{\circ} \mathrm{E}$ \\
\hline Negele, Ethiopia & nege & $5.33^{\circ} \mathrm{N}$ & $39.59^{\circ} \mathrm{E}$ & $3.60^{\circ} \mathrm{S}$ & $111.36^{\circ} \mathrm{E}$ \\
\hline Entebbe, Uganda & ebbe & $0.04^{\circ} \mathrm{N}$ & $32.44^{\circ} \mathrm{E}$ & $9.53^{\circ} \mathrm{S}$ & 104.10 \\
\hline Eldoret, Kenya & moiu & $0.29^{\circ} \mathrm{N}$ & $35.29^{\circ} \mathrm{E}$ & $9.17^{\circ} \mathrm{S}$ & $107.00^{\circ} \mathrm{E}$ \\
\hline Mbarara, Uganda & mbar & $0.60^{\circ} \mathrm{S}$ & $30.74^{\circ} \mathrm{E}$ & $10.22^{\circ} \mathrm{S}$ & $102.38^{\circ} \mathrm{E}$ \\
\hline Kigali, Rwanda & nurk & $1.94^{\circ} \mathrm{S}$ & $30.09^{\circ} \mathrm{E}$ & $11.62^{\circ} \mathrm{S}$ & $101.66^{\circ} \mathrm{E}$ \\
\hline Malindi, Kenya & mal2 & $2.99^{\circ} \mathrm{S}$ & $40.19^{\circ} \mathrm{E}$ & $12.42^{\circ} \mathrm{S}$ & $111.86^{\circ} \mathrm{E}$ \\
\hline Dodoma, Tanzania & dodm & $6.17^{\circ} \mathrm{S}$ & $35.75^{\circ} \mathrm{E}$ & $16.08^{\circ} \mathrm{S}$ & $107.22^{\circ} \mathrm{E}$ \\
\hline Tanzania CGPS, Tanzania & $\tan z$ & $6.77^{\circ} \mathrm{S}$ & $39.21^{\circ} \mathrm{E}$ & $16.59^{\circ} \mathrm{S}$ & $110.65^{\circ} \mathrm{E}$ \\
\hline Tukuyu, Tanzania & tukc & $9.33^{\circ} \mathrm{S}$ & $33.75^{\circ} \mathrm{E}$ & $19.59^{\circ} \mathrm{S}$ & $104.91^{\circ} \mathrm{E}$ \\
\hline Dar es Salaam, Tanzania & $\tan z$ & $6.76^{\circ} \mathrm{S}$ & $39.21^{\circ} \mathrm{E}$ & $16.58^{\circ} \mathrm{S}$ & $110.65^{\circ} \mathrm{E}$ \\
\hline Mzuzu, Malawi & mzuz & $11.43^{\circ} \mathrm{S}$ & $34.00^{\circ} \mathrm{E}$ & $21.88^{\circ} \mathrm{S}$ & $104.91^{\circ} \mathrm{E}$ \\
\hline Lusaka, Zambia & zamb & $15.42^{\circ} \mathrm{S}$ & $28.31^{\circ} \mathrm{E}$ & $26.26^{\circ} \mathrm{S}$ & $98.40^{\circ} \mathrm{E}$ \\
\hline Ngamiland, Botswana & maua & $19.19^{\circ} \mathrm{S}$ & $23.85^{\circ} \mathrm{E}$ & $30.11^{\circ} \mathrm{S}$ & $92.86^{\circ} \mathrm{E}$ \\
\hline Hartebeesthoek, South Africa & hrao & $25.89^{\circ} \mathrm{S}$ & $27.68^{\circ} \mathrm{E}$ & $36.32^{\circ} \mathrm{S}$ & $94.68^{\circ} \mathrm{E}$ \\
\hline \multirow[t]{2}{*}{ Sutherland, South Africa } & suth & $32.38^{\circ} \mathrm{S}$ & $20.81^{\circ} \mathrm{E}$ & $41.09^{\circ} \mathrm{S}$ & $84.76^{\circ} \mathrm{E}$ \\
\hline & \multicolumn{5}{|c|}{ Magnetometer } \\
\hline Addis Ababa, Ethiopia & AAE & $9.0^{\circ} \mathrm{N}$ & $38.8^{\circ} \mathrm{E}$ & $0.14^{\circ} \mathrm{N}$ & $110.50^{\circ} \mathrm{E}$ \\
\hline Adigrat, Ethiopia & ETHI & $14.3^{\circ} \mathrm{N}$ & $39.5^{\circ} \mathrm{E}$ & $6.01^{\circ} \mathrm{N}$ & $111.09^{\circ} \mathrm{E}$ \\
\hline
\end{tabular}


Table 2. Availability of quiet days at the crests and trough

\begin{tabular}{lllll}
\hline Month & Total quiet & \multicolumn{3}{c}{ Total available quiet days } \\
& days & Northern crest & Trough & Southern crest \\
\hline January & 27 & 27 & 27 & 27 \\
February & 24 & 24 & 24 & 24 \\
March & 21 & 21 & 21 & 21 \\
April & 28 & 24 & 28 & 28 \\
May & 22 & 11 & 22 & 22 \\
June & 20 & 20 & 20 & 20 \\
July & 20 & 20 & 20 & 20 \\
August & 19 & 19 & 14 & 19 \\
September & 27 & 27 & 14 & 27 \\
October & 23 & 22 & 23 & 22 \\
November & 24 & 22 & 24 & 24 \\
December & 28 & 28 & 28 & 28 \\
\hline
\end{tabular}


Table 3. Latitudinal extent $(L)$, differential extent and strength of the anomaly $(\triangle T E C)$ for the northern hemisphere (NH) and southern hemisphere (SH).

\begin{tabular}{|c|c|c|c|c|c|}
\hline & \multicolumn{2}{|c|}{ L (degree) } & \multirow{2}{*}{$\begin{array}{c}\text { Differential } \\
\text { extent }\left({ }^{\circ}\right)\end{array}$} & \multicolumn{2}{|c|}{$\triangle T E C$ (TECU) } \\
\hline & $\mathrm{NH}\left({ }^{\circ}\right)$ & $\mathrm{SH}\left({ }^{\circ}\right)$ & & $\mathrm{NH}$ & SH \\
\hline \multicolumn{6}{|c|}{ Month } \\
\hline January & 9 & 19 & 28 & 10.16 & 17.15 \\
\hline February & 9 & 11 & 20 & 11.64 & 9.73 \\
\hline March & 10 & 12 & 22 & 20.24 & 22.87 \\
\hline April & 11 & 13 & 24 & 20.32 & 26.44 \\
\hline May & 9 & 11 & 20 & 9.54 & 23.26 \\
\hline June & 7 & 11 & 18 & 3.18 & 10.39 \\
\hline July & 7 & 8 & 15 & 0.4 & 6.17 \\
\hline August & 9 & 10 & 19 & 6.38 & 13.31 \\
\hline September & 12 & 14 & 26 & 20.17 & 30.24 \\
\hline October & 12 & 12 & 24 & 27.24 & 29.41 \\
\hline November & 12 & 19 & 31 & 23.92 & 27.46 \\
\hline December & 13 & 21 & 34 & 27.56 & 21.57 \\
\hline \multicolumn{6}{|c|}{ Season } \\
\hline Winter & 10.75 & 17.50 & 28.25 & 18.32 & 18.98 \\
\hline Spring equinox & 10.50 & 12.50 & 23.00 & 20.28 & 24.66 \\
\hline Autumn equinox & 12.00 & 13.00 & 25.00 & 23.71 & 29.83 \\
\hline summer & 8.00 & 10.00 & 18.00 & 4.88 & 13.28 \\
\hline
\end{tabular}

